\title{
Raindrop Axis Ratios and Size Distributions in Florida Rainshafts: An Assessment of Multiparameter Radar Algorithms
}

\author{
V. N. Bringi, V. Chandrasekar, Member, IEEE, and Rongrui Xiao, Member, IEEE
}

\begin{abstract}
Eleven penetrations of rainshafts by the University of Wyoming King Air (WKA) aircraft equipped with a twodimensional (2-D) optical array probe are studied in coordination with multiparameter radar measurements from the National Center for Atmospheric Research (NCAR) CP-2 radar collected in a multicellular storm that occurred on August 8, 1991, of the Convective and Precipitation/Electrification (CaPE) experiment. A comparison is made between the mass-weighted mean diameter $\left(D_{m}\right)$ and rainrate $(R)$ computed from the nine-size spectra and their estimates from multiparameter radar algorithms based on $Z_{\mathrm{dr}}$ and $Z_{h}$. It was found that $D_{m}$ could be estimated with a mean bias of $0.07 \mathrm{~mm}$ and a standard deviation of $0.35 \mathrm{~mm}$. Rainrates (in the range of 10-60 $\mathrm{mmh}^{-1}$ ) could be estimated from $Z_{h}$ and $Z_{\mathrm{dr}}$ with a mean bias of $1-4 \%$ and fractional standard error (FSE) of 30-40\% depending on the estimator used. Raindrop axis ratios are analyzed as a function of volume equivalent spherical diameter $\left(D_{e q}\right)$ in the range $2-6 \mathrm{~mm}$. The mean axis ratio versus the $D_{\text {eq }}$ relationship was found to be consistent with previous data from the High Plains (from Colorado and Montana). A study of fluctuations of axis ratio (about their mean value) showed that most drops have axis ratios close to their mean values with oscillation amplitudes to be typically $\pm 10 \%$ in axis ratio, again consistent with the earlier High Plains results.
\end{abstract} tions.

Index Terms - Multiparameter, radar, raindrop, size distribu-

\section{INTRODUCTION}

$\mathbf{P}$ OLARIMETRIC radar rainrate algorithms based on reflectivity $\left(Z_{h}\right)$, differential reflectivity $\left(Z_{\mathrm{dr}}\right)$, and specific differential phase $\left(K_{\mathrm{dp}}\right)$ offer physically based approaches to the measurement of rainfall. These algorithms are generally derived based on 1) equilibrium raindrop shapes via an axis ratio $(a / b)$ versus the $D_{\text {eq }}$ (volume-equivalent spherical diameter) relation [1], [2] and 2) either exponential [3] or gamma drop-size distribution (dsd) [4] or experimentally measured distributions. Quantitative assessments of the improvements of polarimetric algorithms over $Z-R$ relations using simulations of dsd (fluctuations and radar measurement errors have been performed by several investigators [5], [6] based on 1) and 2) above. The mean axis ratio $(a / b)$ versus the $D_{\text {eq }}$ relation is critical for deriving algorithms based on $Z_{\mathrm{dr}}$ or $K_{\mathrm{dp}}$.

Manuscript received November 20, 1996; revised June 13, 1997. This work was supported by the National Science Foundation via Grants ATM-9014600, ATM-9410698, and ATM-9200761.

V. N. Bringi and V. Chandrasekar are with the Department of Electrical Engineering, Colorado State University, Fort Collins, CO 80523 USA (e-mail: bringi@engr.colostate.edu).

R. Xiao was with the Department of Electrical Engineering, Colorado State University, Fort Collins, CO 80523-1373 USA. He is now with Vexcel Corporation, Boulder, CO 80301 USA.

Publisher Item Identifier S 0196-2892(98)01135-8.
There has been much debate on the extent that the mean axis ratio versus the $D_{\text {eq }}$ relation can be biased by raindrop oscillations (e.g., [7], [8]), and quantitative data are lacking for large drops under conditions of moderate-tohigh rainrates. Chandrasekar et al. [7] found that most of the drops had axis ratios close to the mean, with small oscillation amplitudes, typically $10 \%$, in their aircraft-based study from the High Plains (from Colorado and Montana) (rainrates 1-15 $\mathrm{mmh}^{-1}$ ) using two-dimensional (2-D)-Particle Measuring Systems, Inc. (PMS) probe images. In the High Plains data, ice cores in partially melting drops may have suppressed oscillations for drops with $D_{\text {eq }} \geq 4 \mathrm{~mm}$. In the Florida data set reported here, the $0{ }^{\circ} \mathrm{C}$ level is much higher [near 4.8-km altitude mean sea level (msl)] and the penetration altitude is at a much warmer temperature $\left(\sim 15^{\circ} \mathrm{C}\right)$. Thus, the possibility of partially melted drops at the penetration altitude should be extremely small.

One goal of this paper is to extend the Chandrasekar et al. [7] drop axis ratio results to the much higher rainrate conditions (20-60 $\mathrm{mmh}^{-1}$ ) in the Florida environment. A second goal is to quantitatively assess the ability of radarmeasured $Z_{\mathrm{dr}}$ to predict the mass-weighted mean diameter $\left(D_{m}\right)$ of the dsd (assuming equilibrium shapes) by direct comparisons with $D_{m}$ from dsd's measured by the 2-DPMS probe. Effects of large amplitude drop oscillations due to collisional forcing, as suggested by Beard et al. [8], at high rainrates should negatively impact such a comparison. In fact, such comparisons between radar-measured $Z_{\mathrm{dr}}$ and $Z_{\mathrm{dr}}$ computed from dsd data from a distrometer in light rainrate conditions forced Goddard and Cherry [9] to empirically adjust the mean $(a / b)$ versus the $D_{\text {eq }}$ relation (for $D_{\text {eq }}<3$ $\mathrm{mm}$ ) to remove a $0.1-\mathrm{dB}$ bias in the $Z_{\mathrm{dr}}$ comparisons. Later work revealed that their adjustment was in the right direction and that the cause of the upward shift toward sphericity in mean axis ratio was due to raindrop oscillations [7], [10]. A third related goal is the quantitative assessment of several rainrate algorithms based on $Z_{h}$ alone and on $Z_{h}$ and $Z_{\mathrm{dr}}$. These assessments will also be placed in context with theoretical assessments based on simulations of dsd and radar measurement errors. There is a need for such assessment, especially under the higher rainrate conditions reported here. Previous quantitative assessments using ground-based distrometers were generally made under light rainfall conditions [9], [11]. The one aircraft-based experiment using a 2-DPMS probe and the Chilbolton radar [12] also involved light 
rainrate $\left(<10 \mathrm{mmh}^{-1}\right)$ conditions. More recently, quantitative assessments of polarimetric rainrate algorithms have been conducted in heavier convective rainfall using raingages [6], [13]-[15].

A secondary goal is an assessment of a new algorithm to compute X-band-specific attenuation for dual-wavelength reflectivity ratio [16] by comparing radar estimates with specific attenuation computed directly from the measured dsd.

The data reported herein were obtained on August 8, 1991, in east-central Florida during the Convective and Precipitation/Electrification (CaPE) experiment. A multicellular storm was the target of intensive observations by the National Center for Atmospheric Research (NCAR) CP-2 radar and the University of Wyoming King Air aircraft (WKA). The WKA equipped with a 2-D-PMS probe made a series of 11 rainshaft penetrations over a period of $30 \mathrm{~min}$ at altitudes between 250 and $550 \mathrm{~m}$. The storm, located at a range of $60 \mathrm{~km}$ from the CP-2 radar, was scanned with good time resolution [Range Height Indicator (RHI) or Plan Position Indicator (PPI) scan covering the storm every $2 \mathrm{~min}]$. We focus on radar measurements of $Z_{h}$ and $Z_{\mathrm{dr}}$ and the dualwavelength radar estimate of specific attenuation $\left(A_{x}\right)$ at the $10-\mathrm{GHz}$ frequency. The excellent navigation, typically within $100 \mathrm{~m}$, made possible by the Global Positioning System (GPS) receivers on the WKA, ensured that aircraft and radar data could be accurately aligned in space. This requirement is critical for the quantitative assessments reported here in typical Florida cells with diameters $\sim 5 \mathrm{~km}$.

This paper is organized as follows. Section II gives a radar overview of the storm ever a period of about $30 \mathrm{~min}$ via constant altitude PPI sections. Section III describes the results of 2-D-PMS probe image analysis as related to raindrop axis ratios and inferred oscillation amplitudes. Section IV discusses details of four penetrations by comparing $Z_{h}$ and $Z_{\mathrm{dr}}$ from radar and computed from the probe data as a function of time (or, equivalently, position) along the track. Also given are up/down draft speeds and the penetration-averaged dsd. Section $\mathrm{V}$ discusses the quantitative assessments of radarbased inferences against probe data. Section VI concludes the paper with a summary of results. The Appendix details the radar data analysis procedures.

\section{RADAR DATA}

The storm of interest developed around 1730 UTC along a sea-breeze cloud line (visible as towering cumulus clouds from 1430 UTC) near the east-central Florida coast. The Appendix describes details of the multiparameter radar analysis methods used in this work. All radar measurements were obtained with the NCAR CP-2 radar, whose location is the grid origin in all subsequent figures. The environmental sounding taken at around 1700 UTC near the location of the storm showed the $0{ }^{\circ} \mathrm{C}$ level at $4.8 \mathrm{~km}$ and cloud base at $1.2 \mathrm{~km}$. Henceforth, all times will be UTC and all altitudes will be above msl unless otherwise indicated.

Fig. 1 shows a time sequence of constant altitude PPI sections at $4-\mathrm{km}\left(4{ }^{\circ} \mathrm{C}\right)$ altitude from 1734 to 1811 , spaced roughly $7 \mathrm{~min}$ apart. Data from this altitude level enable a clearer depiction of individual cells within the complex in terms of positive $Z_{\mathrm{dr}}$ columns, i.e., areas of $Z_{\mathrm{dr}} \geq 1 \mathrm{~dB}$ near the $0^{\circ}$ level. Panels (a)-(f) show contours of $Z_{h}$ with differential reflectivity $\left(Z_{\mathrm{dr}}, \mathrm{dB}\right)$ as grayscale filled contours; only $Z_{\mathrm{dr}} \geq 1.0 \mathrm{~dB}$ at this level is shown. These panels also show superimposed the WKA tracks at altitudes of 250-550 m as straight-line segments. These segments (identified by time) correspond to the spatial distances over which the dsd's have been averaged for later analysis [described in Section IV(E)].

Prior to 1730 UTC, the storm could be associated with a single cell. The storm was isolated and appeared to have been initiated along a sea-breeze cloud line. After 1730, the storm displayed a multicellular structure, as seen in Fig. 1; separate cells are identified as the NW, S, and SW cells in panels (a), (d), (e), and (f). The signature of positive $Z_{\mathrm{dr}}(\geq 2.0 \mathrm{~dB})$ in the CAPPI sections at altitudes near $4 \mathrm{~km}$ is indicative of updrafts at these levels, as confirmed by aircraft and multiple-Doppler studies in similar Florida cells [17]-[20]. For example, positive $Z_{\mathrm{dr}}$ columns are noted in Fig. 1(a), (c), (d), and (e); this signature is typically due to a low concentration of large raindrops either ascending, descending, or being suspended in the updraft, depending on the terminal fallspeed [21], [22].

Fig. 1(a)-(f) show that the WKA made 11 penetrations of rainshafts between 1745 and 1813. The penetrations at 1745, 1756, 1804, and 1813 are detailed in Section IV-A and B. The 1745 penetration [see Fig. 1(b)] was made during the mature phase of the NW-cell marked in Fig. 1(a). The 1756 penetration [Fig. 1(d)] was also made during the mature phase around $6 \mathrm{~min}$ after the collapse of the positive $Z_{\mathrm{dr}}$ column in Fig. 1(c). The penetrations at 1804 and 1806 were made near the SW-cell [see Fig. 1(e)] during its vigorous growth phase. The last two penetrations at 1811 and 1813 were made during the mature phase of the SW-cell after the positive $Z_{\mathrm{dr}}$ column had weakened [see Fig. 1(f)].

\section{AIRCRAFT DATA}

The principal data source from the WKA was from the 2-D-PMS precipitation probe, which was mounted with horizontal optical axis so that the elliptical cross section of the drops could be imaged. The analysis method used here follows Chandrasekar et al. [7]. The 2-D-PMS precipitation probe has a resolution of $0.2 \mathrm{~mm}$. For each entire image of the drop within the scan area (the minimum $D_{\mathrm{eq}}$ is chosen as $0.75 \mathrm{~mm}$ ), the major $(2 b)$ and the minor $(2 a)$ axes of the principal elliptical cross section are determined via 1) a direct method for $0.75 \leq D_{\text {eq }} \leq 2 \mathrm{~mm}$ and 2) a 2-D filtering method for $D_{\text {eq }} \geq 2 \mathrm{~mm}$. The missing scans at the leading edge of the image are compensated for using the method described in Xiao et al. [23]. The horizontal resolution was recalculated from the measured airspeed and the recorded clock rate, and the adjusted horizontal resolution was used to calculate the horizontal size of the images. The volume equivalent spherical diameter $D_{\text {eq }}$ was estimated from $D_{\text {eq }}=2\left(a b^{2}\right)^{1 / 3}$. In the size distribution plots, all drops with $D_{\text {eq }} \geq 0.75 \mathrm{~mm}$ are shown.

Fig. 2 shows the average distribution from all 11 penetrations with a total sample volume of 621401 . The dashed straight line, which is a fit to the data, has a slope of $15.05 \mathrm{~cm}^{-1}$ and an intercept of $2155 \mathrm{~m}^{-3} \mathrm{~mm}^{-1}$ (which is around a factor of four less than the Marshall-Palmer [24] 


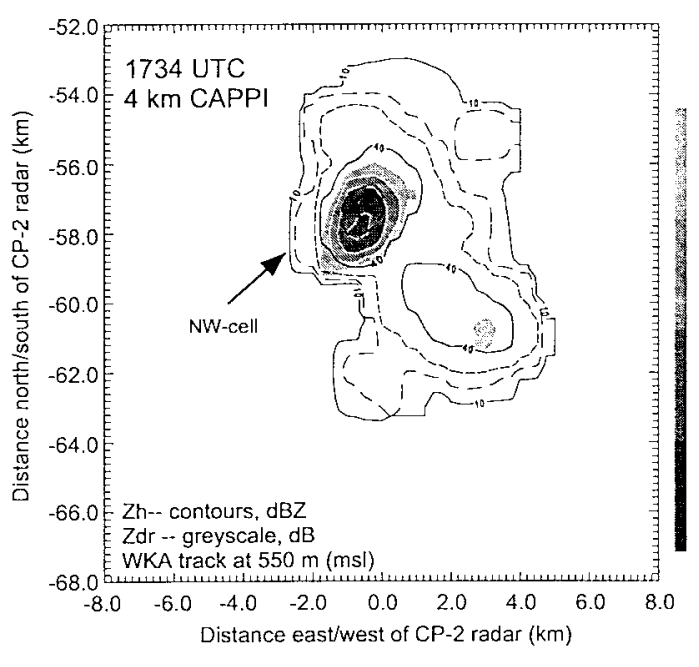

(a)

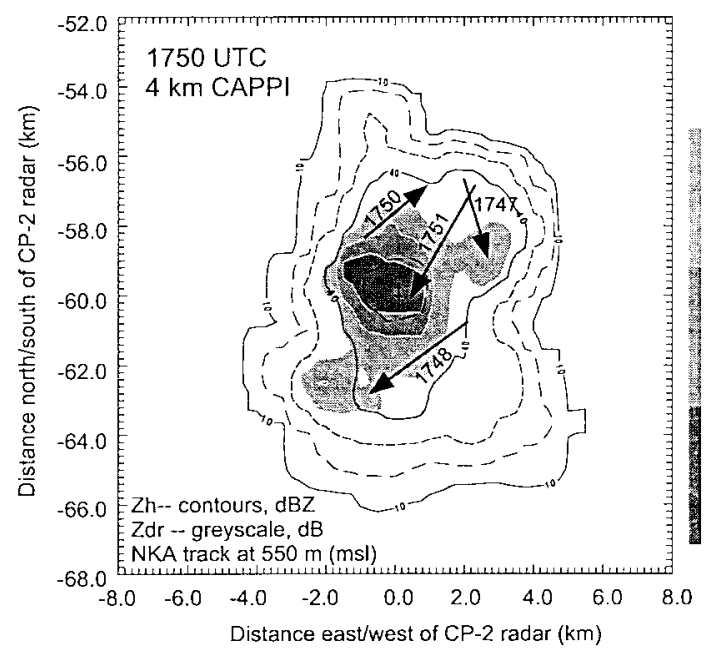

(c)

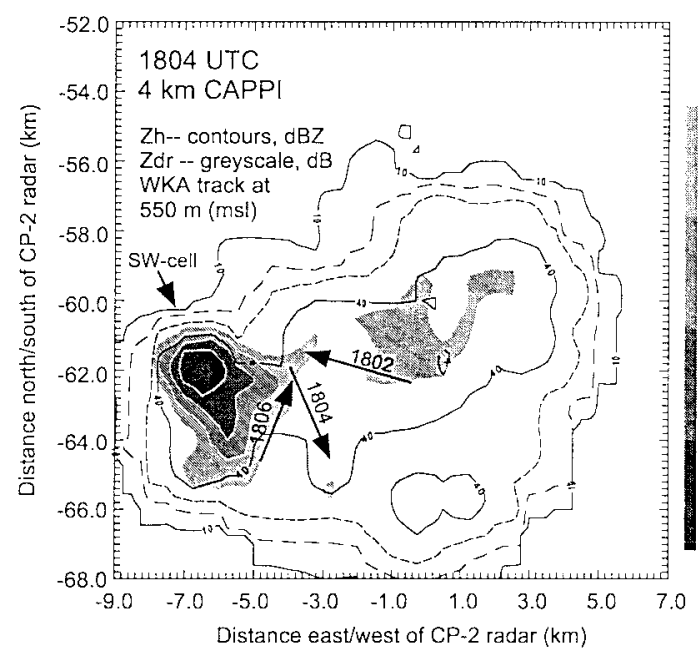

(e)
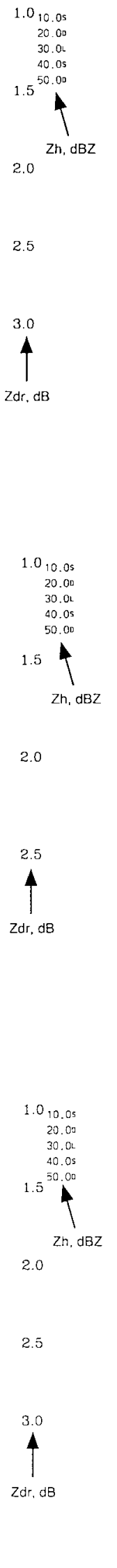

Fig. 1. (a) Constant altitude PPI section at 4-km height showing contours of $Z_{h}$ (starting at $10 \mathrm{dBZ}$ with increments of $10 \mathrm{~dB}$ ) with grayscale overlay of $Z_{\mathrm{dr}}$ (only values exceeding $1 \mathrm{~dB}$ are shown with darker shades representing more positive values). The CP-2 radar location is at the grid origin. (b)-(f) As in (a), except for times as indicated from 1742-1811 UTC. Straight line segments represent the WKA penetrations at the indicated times.
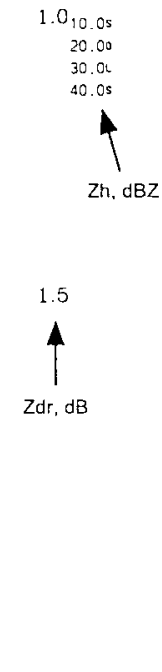

(b)

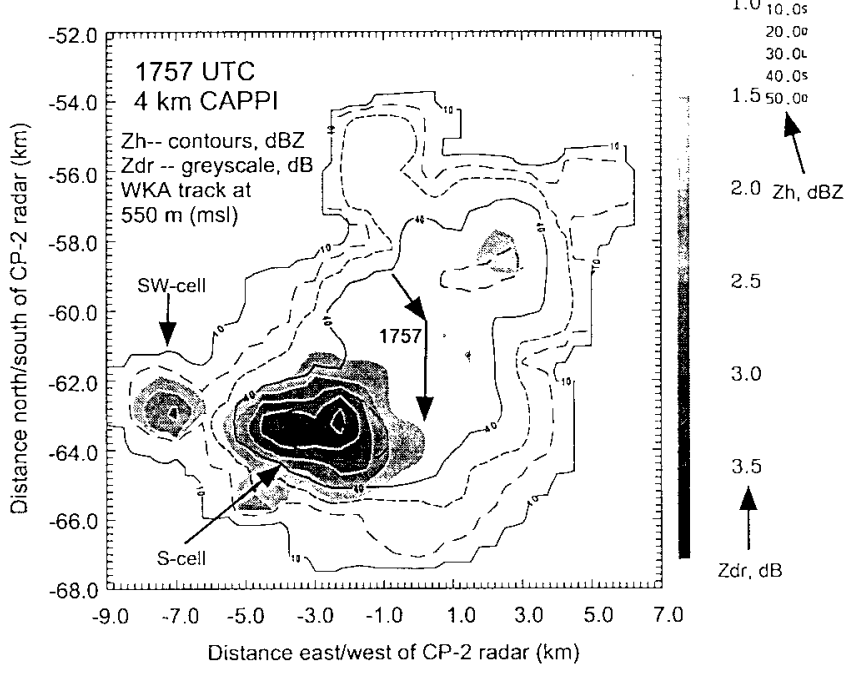

(d)

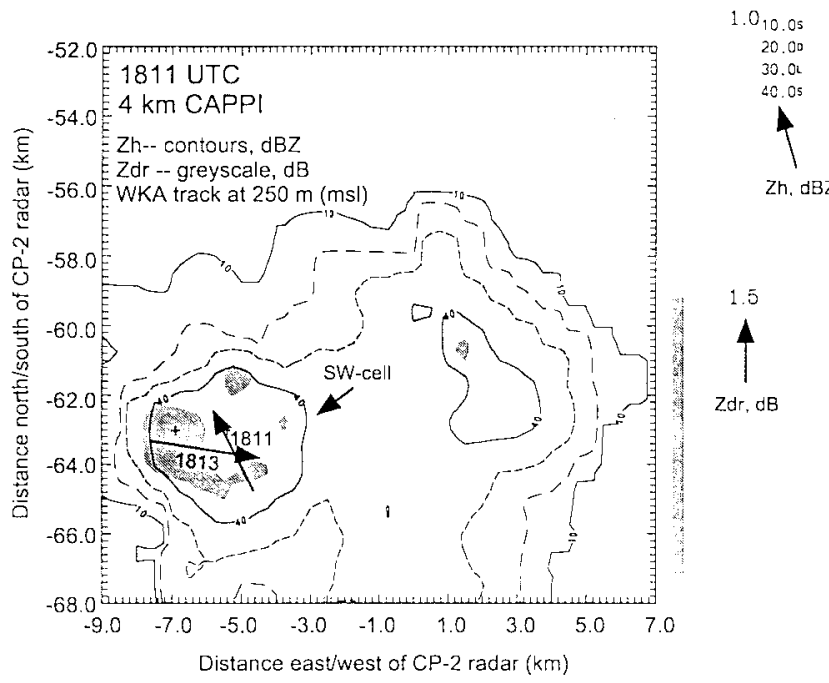

(f) 


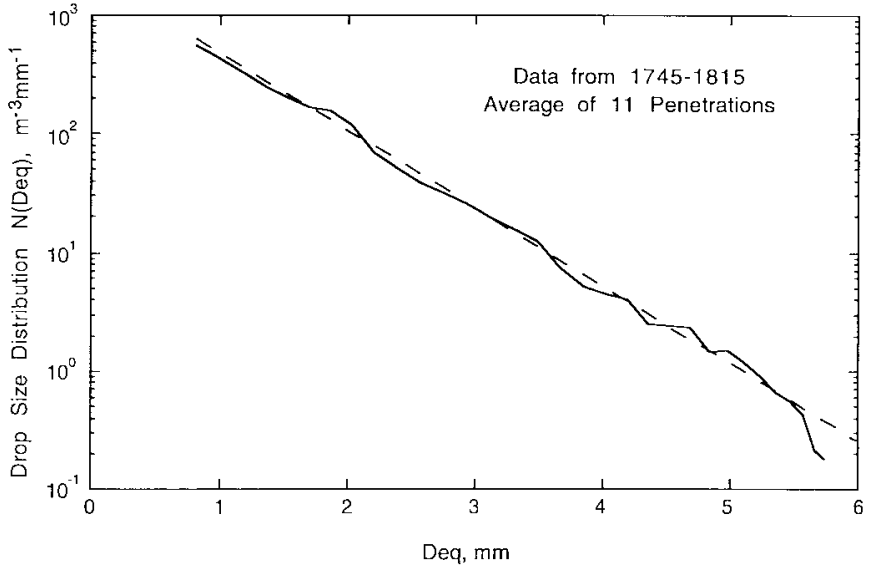

Fig. 2. Dsd (for $D_{\text {eq }} \geq 0.75 \mathrm{~mm}$ ) averaged over all 11 penetrations (see Fig. 1). The dashed straight line is the fit $N\left(D_{\text {eq }}\right)=2155 \exp \left(-1.505 D_{\text {eq }}\right)$. The sample volume is 621401 .

value of 8000). Later, we will compare this averaged slope of $15.05 \mathrm{~cm}^{-1}$ with the slopes from individual penetrations at 1757 and 1813 to illustrate the occurrence of parallel exponential slopes at different rainrates.

\section{A. Raindrop Axis Ratios}

The relation between axis ratio (ratio of minor to major axes $a / b)$ and $D_{\text {eq }}$ for raindrops is fundamental to the interpretation of $Z_{\mathrm{dr}}$ and to the rainrate algorithm based on $Z_{h}$ and $Z_{\mathrm{dr}}$. We note here, in passing, that it is also fundamental to specific differential phase $\left(K_{\mathrm{dp}}\right)$ and on rainrate algorithms using $K_{\mathrm{dp}}$ or $K_{\mathrm{dp}}$ combined with $Z_{\mathrm{dr}}$. As shown by Chandrasekar $e t$ al. [7], it is possible to accurately estimate (within a few percent for $D_{\text {eq }} \geq 2 \mathrm{~mm}$ ) axis ratios of drops from 2-DPMS probe images. The first results from Chandrasekar et al. [7] were from rainshafts in the High Plains with rainrate ranging $1-15 \mathrm{mmh}^{-1}$. The Florida results presented here in rainshafts with significantly higher rainrates $\left(10-60 \mathrm{mmh}^{-1}\right)$ and in warm-based clouds greatly expand the database on raindrop axis ratios.

Fig. 3(a) shows the mean axis ratio $(\langle a / b\rangle)$ versus $D_{\text {eq }}$ for all drops (numbering 3523) with $D_{\mathrm{eq}} \geq 2 \mathrm{~mm}$ from all the penetrations between 1745 and 1815 . The vertical bars represent the $95 \%$ confidence interval for $\langle a / b\rangle$. Also shown are the mean $\langle a / b\rangle$ from Chandrasekar et al. [7] as well as the model fit for equilibrium-shaped drops from Beard and Chuang [2] and the straight-line fit to the windtunnel results of Pruppacher and Beard [1]; i.e., $a / b=$ $1.03-0.062\left(D_{\text {eq }}\right)$, where $D_{\text {eq }}$ is in $\mathrm{mm}$. Between 2 and $2.7 \mathrm{~mm}$, the Florida results show a larger $\langle a / b\rangle$ compared to the Beard and Chuang model results as well as to the earlier Chandrasekar et al. [7] results. Because the 2-D-PMS probe has a resolution of $0.2 \mathrm{~mm}$, the axis ratio estimates for the smaller drops ( $D_{\mathrm{eq}} \sim 2 \mathrm{~mm}$ ) will be less precise than for the larger ones $\left(D_{\mathrm{eq}} \geq 3 \mathrm{~mm}\right)$. Thus, we are not confident about the magnitude of the upward shift in axis ratio at $D_{\text {eq }}=2.2 \mathrm{~mm}$. However, this trend toward higher $\langle a / b\rangle$ for $2 \leq D_{\text {eq }} \leq 2.7 \mathrm{~mm}$ is qualitatively consistent with the empirical adjustment made by Goddard and Cherry [9] and with the laboratory results of Kubesh and Beard [25].

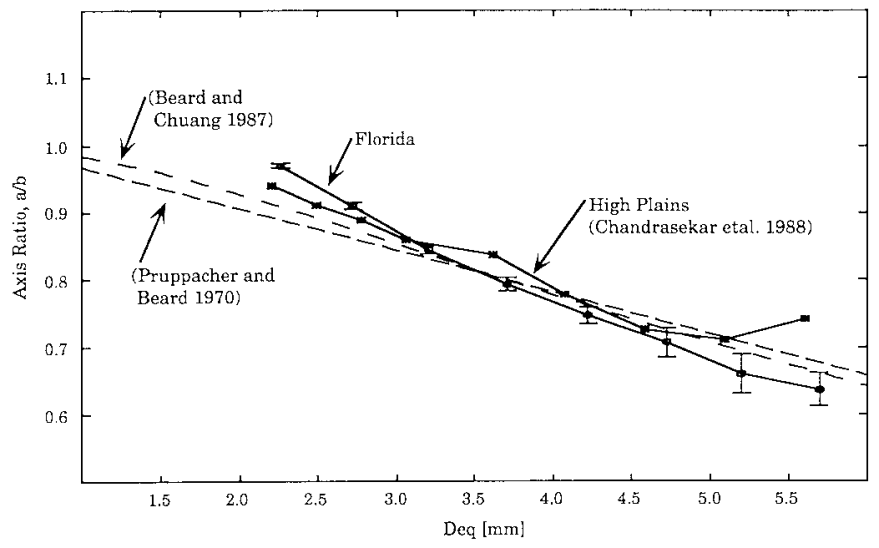

(a)

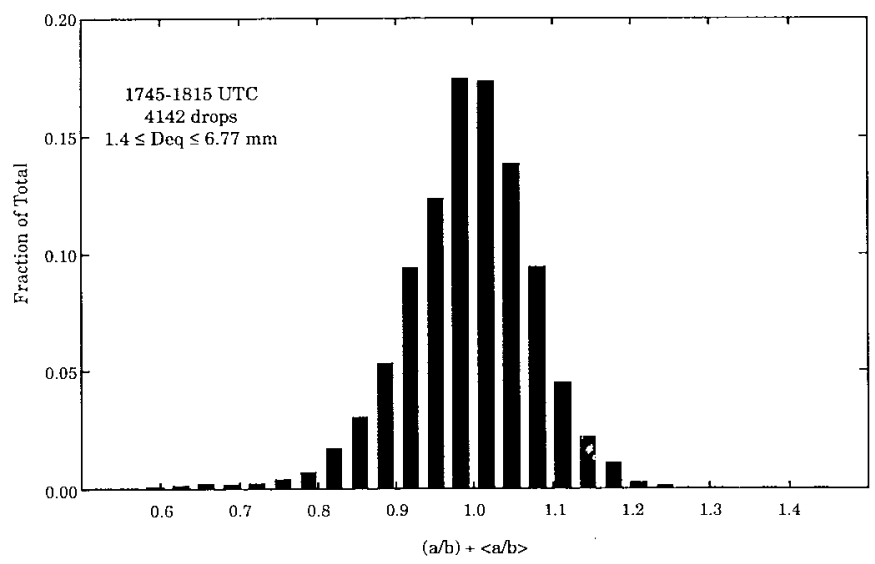

(b)

Fig. 3 (a) Mean axis ratio $(a / b)$ versus $D_{\text {eq }}$ from all 11 penetrations (marked as Florida). Both mean and 95\% confidence interval are shown for the Florida data set. Also shown are the mean results from the High Plains and the model result for equilibrium shapes from Beard and Chuang [2]. The straight line fit $\left(a / b=1.03-0.062 D_{\text {eq }}\right)$ to the wind-tunnel data of Pruppacher and Beard [1] is also shown. (b) Frequency distribution (histogram) for the ratio $(a / b) \div\langle a / b\rangle$, where $\langle a / b\rangle$ is the mean value shown in (a). The measured axis ratio for each drop was divided by the mean axis ratio in the corresponding size $\left(D_{\text {eq }}\right)$ interval to obtain the values that were histogrammed.

For $3 \leq D_{\text {eq }} \leq 4.5 \mathrm{~mm}$, Fig. 3(a) shows that the mean axis ratios are in very good agreement with Beard and Chuang's [2] model and fall within their upper and lower bound results [only their mean model curve is shown in Fig. 3(a)]. For $4.5<D_{\text {eq }} \leq 5.7 \mathrm{~mm}$, the Florida results are very close to the lower bound result of Beard and Chuang [2] and to the empirical fit recommended by Clift et al. [26].

Fig. 3(b) shows a histogram of $a / b \div\langle a / b\rangle$ for all drops with $D_{\text {eq }} \geq 1.5 \mathrm{~mm}$. The measured axis ratio for each drop was divided by the mean axis ratio in the corresponding size $\left(D_{\text {eq }}\right)$ interval to obtain the values that make up the histogram. The histogram shape in Fig. 3(b) is very similar to the results of Chandrasekar et al. [7], with the mode of the distribution being close to unity. One straightforward explanation is that most of the drops have axis ratios close to the mean [shown in Fig. 3(a)] with small oscillation amplitudes, typically, $\pm 10 \%$ in axis ratio. Thus, while raindrops do oscillate, the mean axis ratio of drops with $D_{\text {eq }}$ in the range $3-5.7 \mathrm{~mm}$ is not altered significantly from the equilibrium shape results of Beard and Chuang [2]. This result contradicts the hypothesis of Beard et 
al. [8] regarding collisional forcing of large amplitude drop oscillations and the resulting upward shift in mean axis ratio at higher rainrates. Recently, Tokay and Beard [27] argued that collisions cannot be a major source of drop oscillations since they observed significant numbers of oscillating drops, even through their estimated influence of collisions was clearly negligible.

\section{RADAR/AIRCRAFT INTERCOMPARISONS}

Because of the high degree of navigational accuracy provided by GPS receivers on the WKA, it was possible to compare radar measured $Z_{h}$ and $Z_{\mathrm{dr}}$ along the aircraft track with corresponding calculations from 2-D-PMS probe data. We illustrate such detailed comparisons for four penetrations at 1745, 1756, 1804, and 1813 [see Fig. 1(b), (d), (e), and (f)].

\section{A. 1745 and 1756 Penetrations}

The NW-cell marked in Fig. 1(a) was penetrated on its north side by the WKA at 1745 . Fig. 4 summarizes the comparison between radar and processed 2-D-PMS probe data. Fig. 4(a) is generated as follows. Since the radar $Z_{h}$ is interpolated to a Cartesian grid with grid spacing of $0.25 \mathrm{~km}$, values of $Z_{h}$ closest to the WKA track [shown in Fig. 1(b)] are extracted for each second of flight time, beginning at the start of the penetration noted in Fig. 4(a). Since the WKA penetration time (1745) fell in between two radar volumes, $Z_{h}$ data from two volumes (centered at 1744 and 1747) were averaged (in linear sense, i.e., units of $\mathrm{mm}^{6} \mathrm{~m}^{-3}$ ) and plotted in Fig. 4(a) versus aircraft penetration time (the WKA airspeed was approximately $80 \mathrm{~ms}^{-1}$ ). Similarly, $Z_{\mathrm{dr}}$ from radar is plotted in Fig. 4(b). Also plotted in Fig. 4(a) and (b) are $Z_{h}$ and $Z_{\mathrm{dr}}$, respectively, computed from the 2-D-PMS probe measurements as follows. Starting from 1745:30, bins of 500 raindrops are accumulated sequentially in time and a size spectrum is obtained for each bin from which $Z_{h}$ and $Z_{\mathrm{dr}}$ are computed and plotted versus the center time of the bin. The $Z_{h}$ is approximately computed as $\left\langle D_{\mathrm{eq}}^{6} N\left(D_{\text {eq }}\right)\right\rangle$ over the bin of 500 drops where the drops are assumed to be spherical (later we use rigorous scattering methods for oblate shapes to calculate $Z_{h}$ ). The $Z_{\mathrm{dr}}$ is also approximately computed by first calculating the reflectivity-weighted mean axis ratio for the bin of 500 drops and then, using a simple relation from Jameson [28] to calculate $Z_{\mathrm{dr}}, 10^{-0.1\left(Z_{\mathrm{dr}}\right)}=(a / b)^{7 / 3}$. The straight-line fit to Pruppacher and Beard [1], i.e., $a / b=1.03-0.062 D_{\mathrm{eq}}$ ( $D_{\text {eq }}$ in $\mathrm{mm}$ ), is used for these figures [see Fig. 3(a)]. These approximations are sufficient to show that good correlation can be achieved between the radar and 2-D-PMS measurements, in spite of large sample volume differences. Also, the axis ratios from the consecutive bins of 500 drops are not used to calculate $Z_{\mathrm{dr}}$ since such a small sample cannot accurately estimate the mean axis ratio, especially for the large drops $(>3 \mathrm{~mm})$. Over the $3.2-\mathrm{km}$ penetration segment, the $Z_{h^{-}}$ gradients from radar are less than $\sim 8 \mathrm{dBkm}^{-1}$. There is a general tendency for the radar measurements to "smooth" the 2-D-PMS-based data. This spatial smoothing effect is caused by the antenna beam pattern (at a range of typically $60 \mathrm{~km}$ to the cell, the $3-\mathrm{dB}$ beamwidth of around $1^{\circ}$ produces a crossbeam width of $1 \mathrm{~km}$ ). Fig. 4(c) shows the up/down draft speed from aircraft data with downdrafts up to $-5 \mathrm{~ms}^{-1}$ during this penetration. Fig. 4(d) shows the averaged size distribution for $D_{\mathrm{eq}} \geq 0.75 \mathrm{~mm}$. The dashed line is a straight-line fit to the exponential distribution $N\left(D_{\mathrm{eq}}\right)=N_{0} \exp \left(-\Lambda D_{\mathrm{eq}}\right)$. The rainrate $R$, the mass-weighted mean diameter $\left(D_{m}\right)$ defined as $\left\langle D_{\mathrm{eq}}^{4} N\left(D_{\mathrm{eq}}\right)\right\rangle \div\left\langle D_{\mathrm{eq}}^{3} N\left(D_{\mathrm{eq}}\right)\right\rangle$, and $\Lambda$ are, respectively, $32.6 \mathrm{mmh}^{-1}, 2.6 \mathrm{~mm}$, and $14.7 \mathrm{~cm}^{-1}$.

The WKA penetration in the region of most uniform reflectivity of all 11 penetrations occurred between 1756:00 and 1756:54 [see Fig. 1(d)]. Fig. 5 shows the results of the radar/aircraft comparison, similar to Fig. 4 . The $Z_{h}$ comparison is excellent, while $Z_{\mathrm{dr}}$ from the 2-D-PMS probe data slightly underestimates the radar $Z_{\mathrm{dr}}$. Again, weak downdrafts prevail. The rainrate calculated from Fig. $5(\mathrm{~d})$ is $53.4 \mathrm{mmh}^{-1}$ [only the 1751 penetration, see Fig. 1(c), had a higher value of $57.8 \mathrm{mmh}^{-1}$, which is the largest rate of all the penetrations]. In fact, both the 1751 and 1756 penetrations occurred within the same general area of the cell. The parameter $D_{m}=2.31 \mathrm{~mm}$, while $\Lambda=15.9 \mathrm{~cm}^{-1}$.

\section{B. 1804 and 1813 Penetrations}

Two WKA penetrations at 1804 and 1813 are next discussed. At 1804 , the WKA penetrated a high $Z_{\mathrm{dr}}$ region $\left(Z_{\mathrm{dr}}>3 \mathrm{~dB}\right)$ with high $Z_{h}(\sim 50 \mathrm{dBZ})$. The timing of this penetration was during the growth phase of the SW-cell.

The radar/aircraft comparisons are shown in Fig. 6. In Fig. 6(a), note the $Z_{h}$-gradient from radar around $15 \mathrm{dBkm}^{-1}$ nearly coincident with the $Z_{h}$-gradient from the 2-D-PMS data. The same holds true for the $Z_{\mathrm{dr}}$-gradient in Fig. $6(\mathrm{~b})$. The up/downdraft speed is shown in Fig. 6(c), again with weak downdrafts around 0 to $-2 \mathrm{~ms}^{-1}$. The size distribution in Fig. 6(d) shows a "flat" tail for $D_{\text {eq }}>3.5 \mathrm{~mm}$. The rainrate is $16.8 \mathrm{mmh}^{-1}$ and $D_{m}=3.24 \mathrm{~mm}$. Personnel aboard the WKA reported strong evidence of drop sorting with big raindrops on the southwest side of the storm complex [see Fig. 1(e)]. Because of an excess of big drops in the distribution, the $Z_{h}$ is large but $R$ is much smaller than expected from the usual $Z_{h}-R$ relations. It is precisely under such circumstances that knowledge of $Z_{\mathrm{dr}}$ is important.

The WKA made a repeat penetration of the high $Z_{\mathrm{dr}}$ region at 1806 [see Fig. 1(e)]. The shape of the distribution (not shown here) was nearly identical to Fig. 6(d). The rainrate was $8 \mathrm{mmh}^{-1}$, the lowest value of all the penetration segments, while $D_{m}=3.26 \mathrm{~mm}$. Again, an excess of big drops gives a high $Z_{h}(\sim 45 \mathrm{dBZ})$ and lower $R$ than expected from $Z_{h}-R$ relations.

The WKA made its last two penetrations at 1811 and 1813, closer to the cell's center and during its mature phase [see Fig. 1(f)]. Fig. 7 shows the radar/aircraft comparison for the 1813 penetration. The correlation between radar- and aircraft-derived $Z_{h}$ and $Z_{\mathrm{dr}}$ is comparable to the earlier penetrations. From the size spectrum in Fig. 7(d), the rainrate is $27.8 \mathrm{mmh}^{-1}, D_{m}=2.5 \mathrm{~mm}$, and $\Lambda=15.8 \mathrm{~cm}^{-1}$. This slope is nearly identical to the 1756 penetration (15.9 $\left.\mathrm{cm}^{-1}\right)$, whereas the rainrate at $1756\left(53 \mathrm{mmh}^{-1}\right)$ is nearly twice the value at $1813\left(27.8 \mathrm{mmh}^{-1}\right)$. This result contradicts the Marshall-Palmer [24] relation between $\Lambda$ and $R$ given 


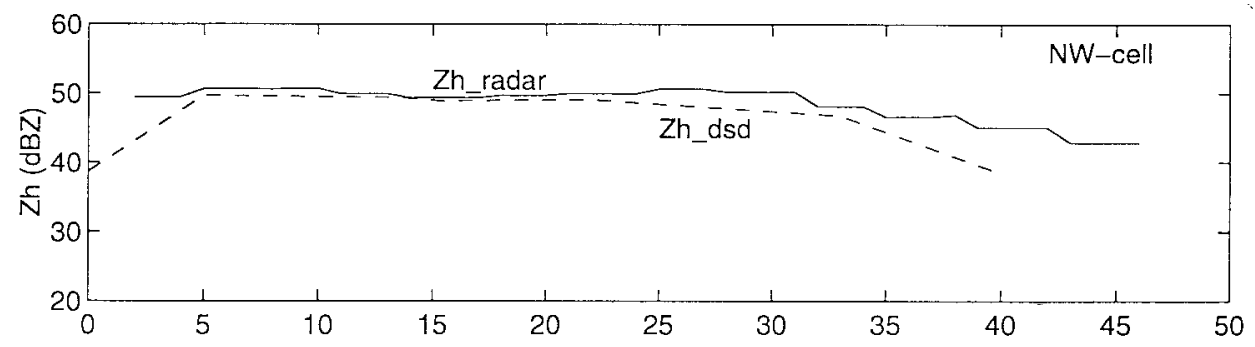

(a)

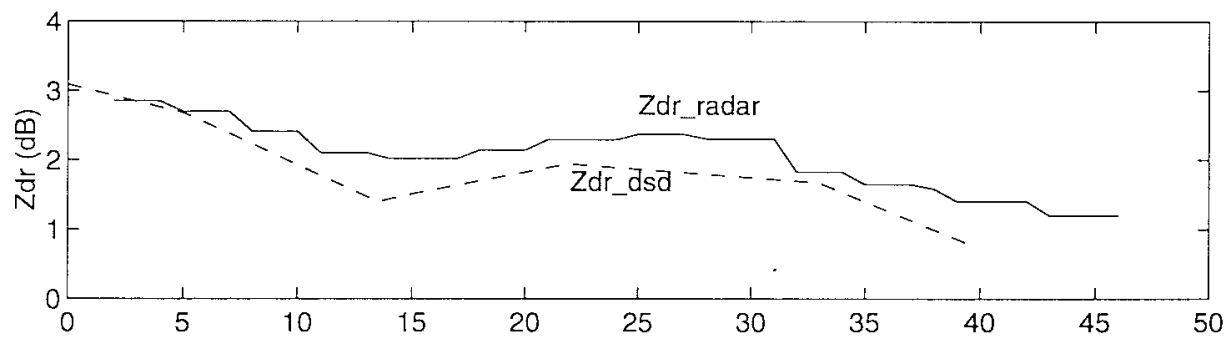

(b)

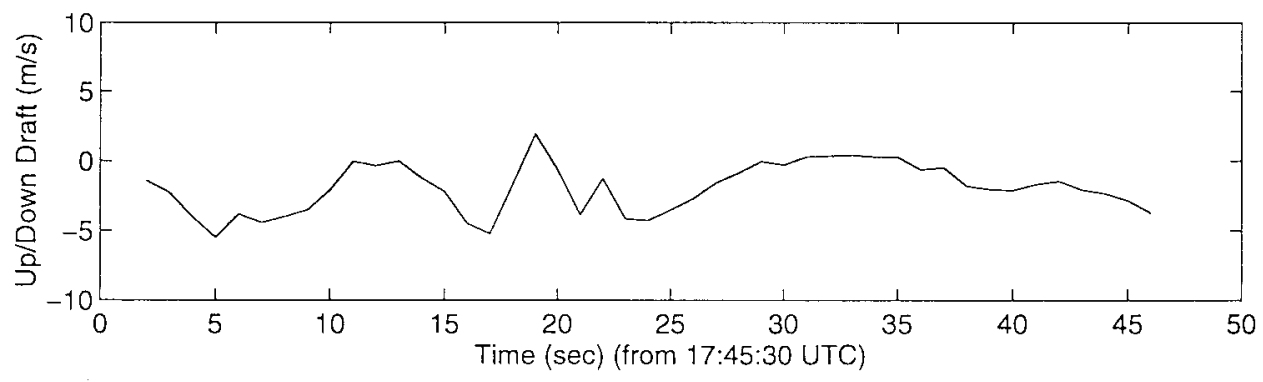

(c)

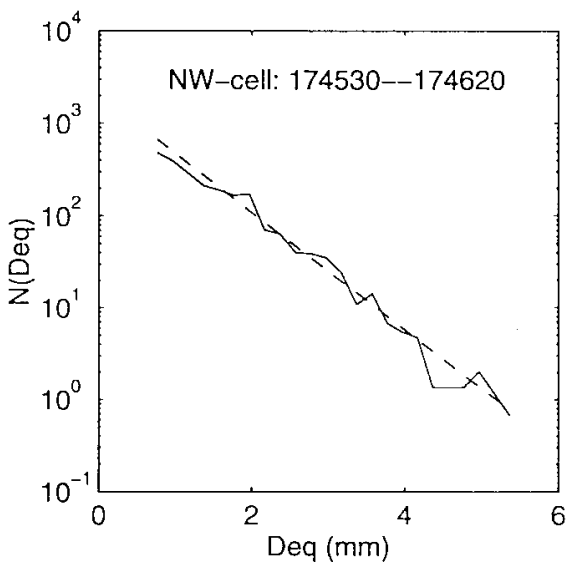

(d)

Fig. 4. (a) Radar measured $Z_{h}\left(Z_{h \text {-radar }}\right)$ compared with $Z_{h}$ calculated from dsd ( $\left.Z_{h \text {-dsd }}\right)$ along the WKA track corresponding to the 1745 penetration [see Fig. 1(b)]. Abscissa corresponds to time from the start of the penetration. (b) As in (a), except $Z_{\mathrm{dr}}$ is compared. (c) Up/down drafts measured by aircraft. (d) Average dsd for the penetration. The dashed straight line is the fit $N\left(D_{\text {eq }}\right)=2048 \exp \left(-1.47 D_{\text {eq }}\right)$. The still-air rainfall rate is 32.6 $\mathrm{mmh}^{-1}$ and $D_{m}=2.6 \mathrm{~mm}$. The sample volume is $7420 \mathrm{l}$.

as $\Lambda=41 R^{-0.21}$, which yields $\Lambda$ of $17.8\left(20.4 \mathrm{~cm}^{-1}\right)$ for $R=53\left(28 \mathrm{mmh}^{-1}\right)$. A large number of dsd's summarized by $\mathrm{Hu}$ and Srivastava [29] show this tendency for parallel exponential slopes (at large $D_{\text {eq }} \geq 2 \mathrm{~mm}$ ), with an average slope around $20 \mathrm{~cm}^{-1}$ for $R$ ranging from 20 to $200 \mathrm{mmh}^{-1}$. Such "equilibrium" distributions are thought to occur when the binary processes of drop breakup and coalescence are in balance [29]. Even when all 11 penetrations are averaged (Fig. 2), the slope $\Lambda=15.05 \mathrm{~cm}^{-1}$ is only slightly less than the slope for the individual 1756 and 1813 penetrations. This slight decrease is caused by the inclusion of "flat" tail spectra at 1804 [see Fig. 6(d)] and 1806. 


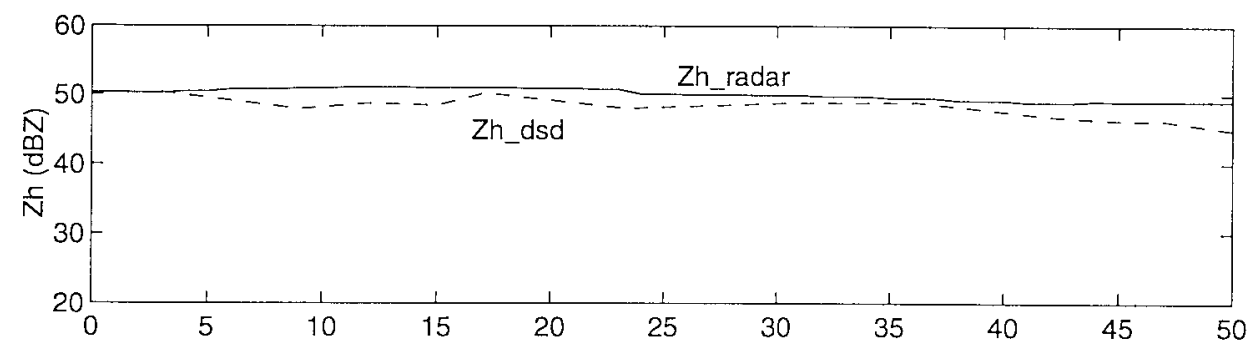

(a)

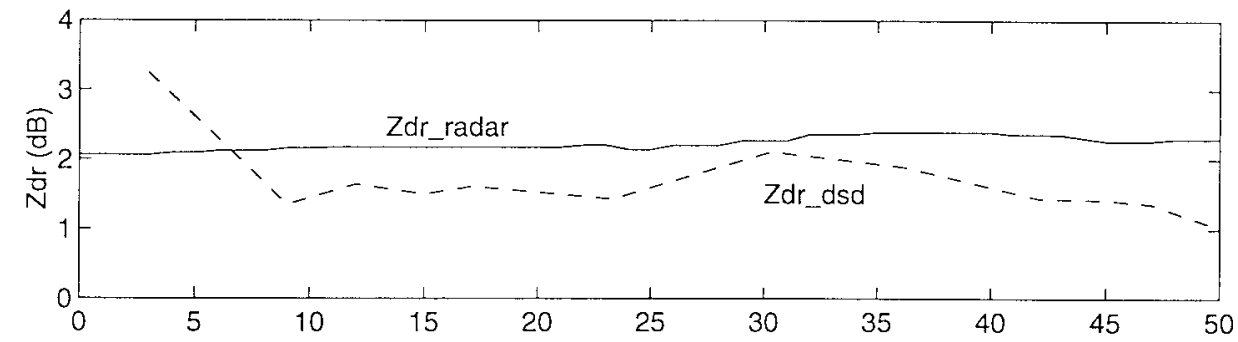

(b)

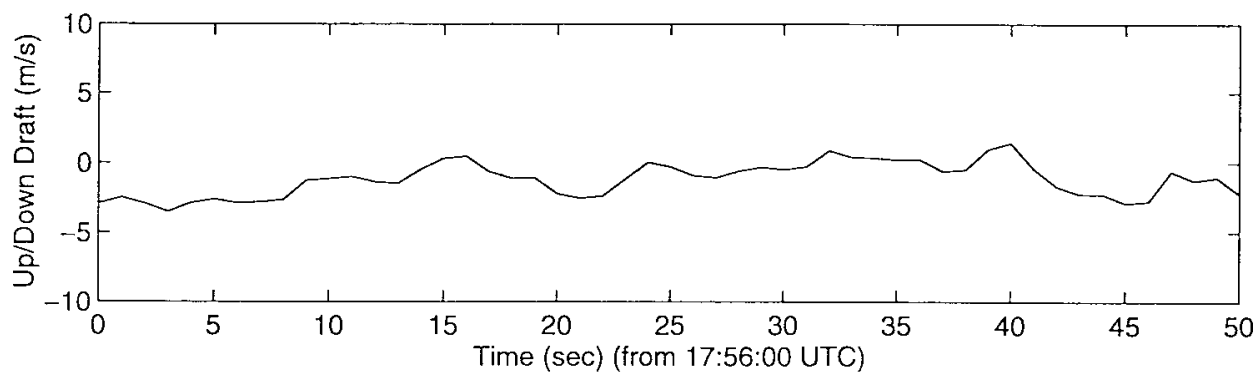

(c)

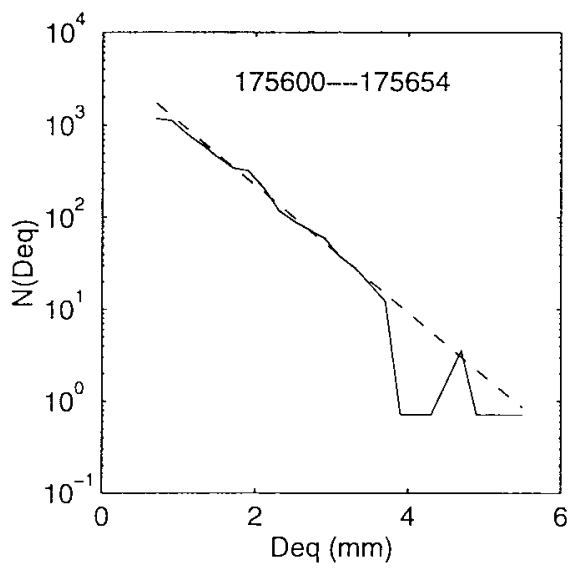

(d)

Fig. 5. As in Fig. 4, except comparison is for the 1757 penetration [see Fig. 1(d)]. (d) The dashed line corresponds to $N\left(D_{\text {eq }}\right)=5290$ exp $\left(-1.59 D_{\text {eq }}\right)$. The still-air rainfall rate is $53.4 \mathrm{mmh}^{-1}, D_{m}=2.31 \mathrm{~mm}$ and sample volume is 70141 .

\section{Penetration-Averaged COMPARisons}

For all 11 penetration segments from 1745-1816, plots similar to those shown in Figs. 4-7 were examined to select those segments where the radar $Z_{h}$ gradients were less than $10 \mathrm{dBkm}^{-1}$ to avoid biases due to antenna beam smoothing. Except for the penetration segments at 1804 and 1806 , the remaining nine segments typically had $Z_{h}$ gradients $\leq 5 \mathrm{dBkm}^{-1}$. Henceforth, our analysis will exclude the 1804 and 1806 segments. From the size spectrum obtained over the duration of each of the nine penetration segments [for example, such as those shown in Figs. 4(d) through 7(d)], we computed using the $T$-matrix method [30] parameters, such as reflectivity at horizontal polarization $\left(Z_{h}\right)$ and specific attenuation at $\mathrm{X}$-band $(10 \mathrm{GHz})$ at horizontal polarization. 


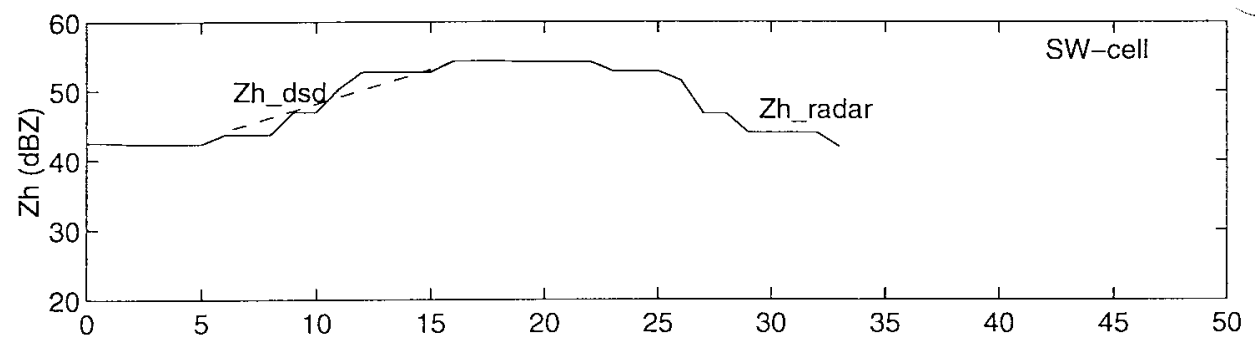

(a)

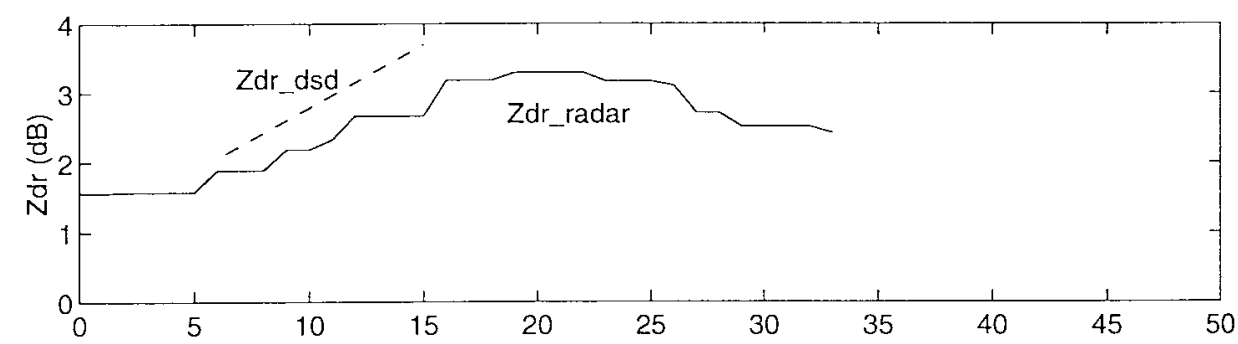

(b)

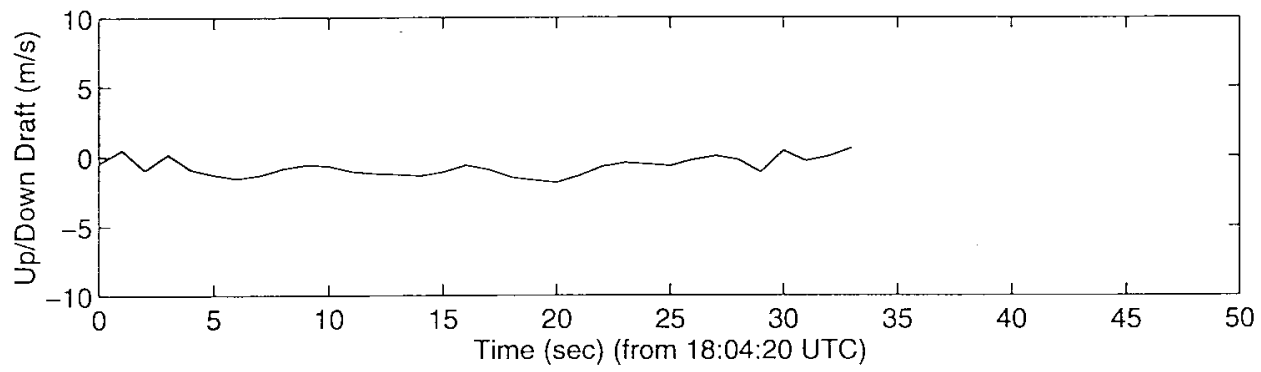

(c)

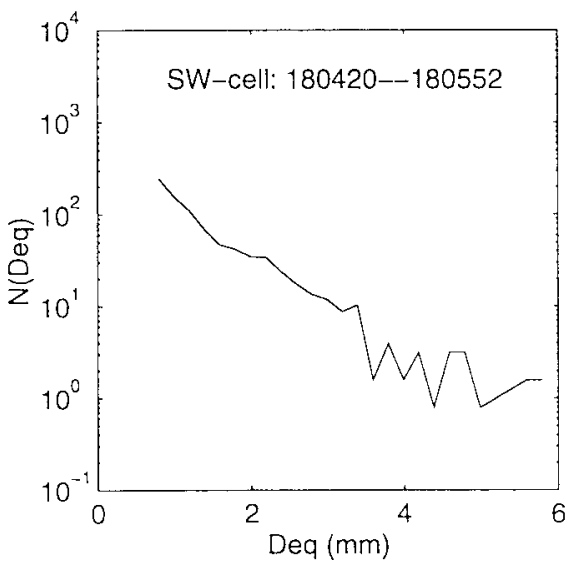

(d)

Fig. 6. As in Fig. 4, except comparison is for the 1804 penetration [see Fig. 1(e)]. (d) The still-air rainfall rate is $16.8 \mathrm{mmh}^{-1}, D_{m}=3.24 \mathrm{~mm}$ and sample volume is 63221 .

The raindrops are modeled as oblate spheroids with the symmetry axis of the spheroids oriented vertically, and the dielectric constant of water at a temperature of $25^{\circ} \mathrm{C}$ is obtained at 3 and $10 \mathrm{GHz}$ [31]. From each of the nine size spectra, we also computed rainrate $R$ (in still air) and massweighted mean diameter $\left(D_{m}\right)$. The penetration-averaged radar parameters were computed as follows from radar data shown, for example, in Figs. 4(a) and (b) through 7(a) and (b). For each segment, the radar $Z_{h}$ along the track is averaged (in linear sense, i.e., converted to $\left.\mathrm{mm}^{6} \mathrm{~m}^{-3}\right)$ to give $\left\langle Z_{h}\right\rangle$. The average $Z_{\mathrm{dr}}$ is computed as $\left\langle Z_{h}\right\rangle-\left\langle Z_{v}\right\rangle$, where $Z_{h}$ and $Z_{v}$ are separately averaged in linear sense. The specific attenuation $A_{x}$ is averaged in units of $\mathrm{dBkm}^{-1}$. Several algorithms are used to compute penetration-averaged rainrate $\langle R\rangle$ based on $Z_{h}$ alone and based on $Z_{h}$ and $Z_{\mathrm{dr}}$. For example, $\langle R\rangle$ from algorithms based on $Z_{h}$, such as $R=a Z_{h}^{b}$, is obtained as $\left\langle a Z_{h}^{b}\right\rangle$ rather than $a\left(\left\langle Z_{h}\right\rangle\right)^{b}$ and similarly for $\langle R\rangle$ based on $Z_{h}$ and $Z_{\mathrm{dr}}$. 


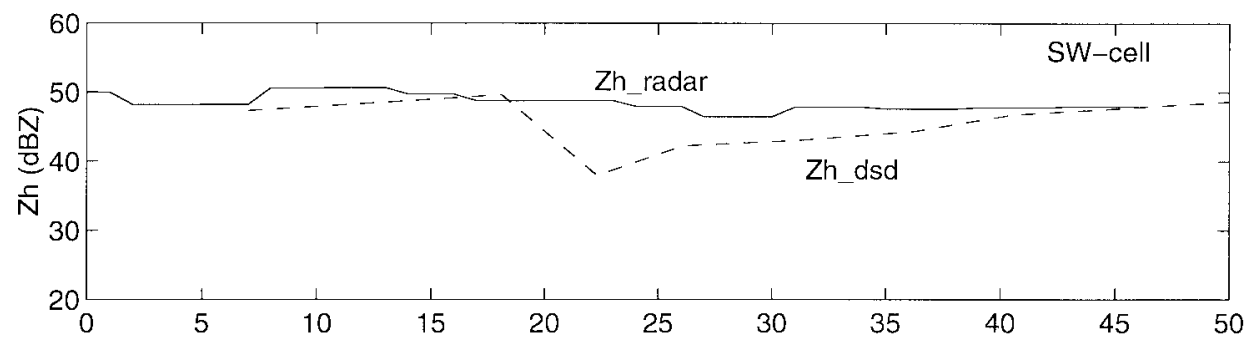

(a)

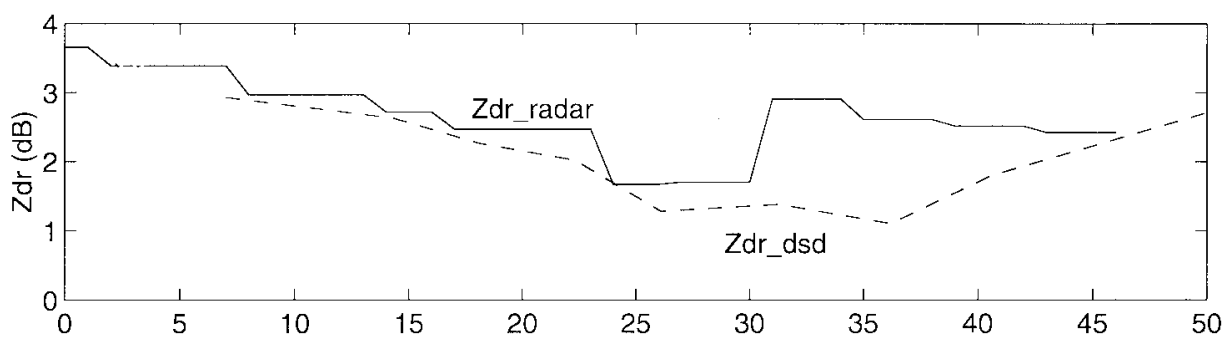

(b)

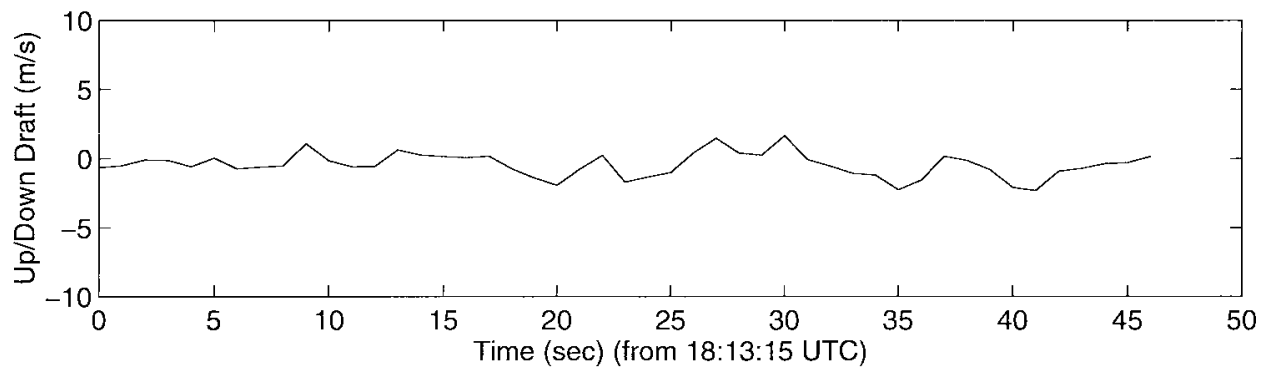

(c)

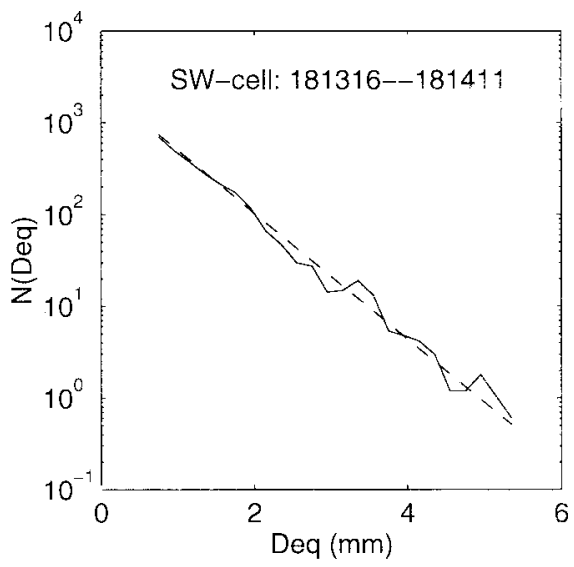

(d)

Fig. 7. As in Fig. 4, except comparison is for the 1813 penetration [see Fig. 1(f)]. (d) The dashed line corresponds to $N\left(D_{\mathrm{eq}}\right)=2436 \exp \left(-1.58 D_{\mathrm{eq}}\right)$. The still-air rainfall rate is $27.8 \mathrm{mmh}^{-1}, D_{m}=2.5 \mathrm{~mm}$ and sample volume is 83121 .

Fig. 8 shows the scatter plot of penetration-averaged $Z_{h}$ (or $\left.\left\langle Z_{h}\right\rangle_{\text {radar }}\right)$ and computed from the size distribution $\left(\left\langle Z_{h}\right\rangle_{\mathrm{dsd}}\right)$. The bias $(B)$ is defined as

$$
B=\frac{1}{N}\left\{\sum_{i=1}^{N} y_{i}-\sum_{i=1}^{N} x_{i}\right\}
$$

and the fractional standard error (FSE) as

$$
\mathrm{FSE}=\left[\frac{1}{N} \sum_{i=1}^{N}\left(y_{i}-x_{i}\right)^{2}\right]^{1 / 2} \div\left[\frac{1}{N} \sum_{i=1}^{N} x_{i}\right]
$$

where $N$ is the number of penetration segments ( $N=9$ for this and all subsequent scatter plots), $y_{i}$ is penetration-averaged ordinate values based on radar measurements, and $x_{i}$ is abscissa values based on penetration-averaged size distribution calculations. In Fig. 8, the bias is only $-0.41 \mathrm{~dB}$. As discussed in the Appendix, the CP-2's radar constant was adjusted using the technique described in Chandrasekar et al. [5] by using time series data from August 24, 1991. The excellent bias result in Fig. 8 is due to this adjustment scheme, which compares $R\left(Z_{h}, Z_{\mathrm{dr}}\right)$ with $R\left(K_{\mathrm{dp}}\right)$ in rainfall. Note that the CP-2 


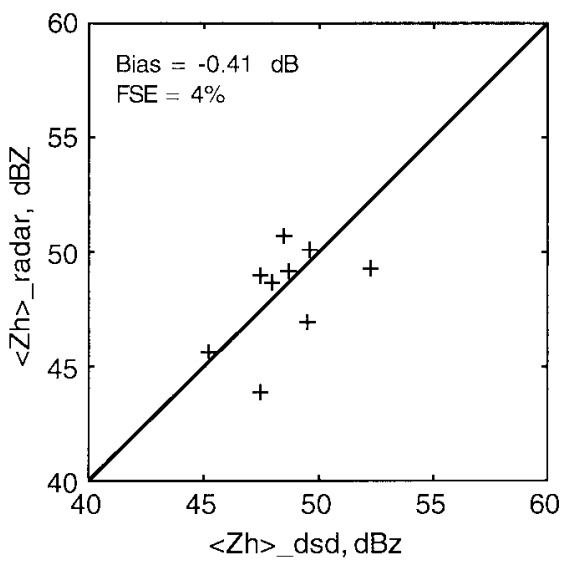

Fig. 8. Scatter plot of (penetration-averaged) radar measured $Z_{h}$ $\left(\left\langle Z_{h \text {-radar }}\right\rangle\right)$ versus $Z_{h}$ computed from (penetration-averaged) dsd $\left(\left\langle Z_{h \text {-dsd }}\right\rangle\right)$.

radar's signal processor could not compute $K_{\mathrm{dp}}$ in real-time during CaPE. The August 24th data were obtained in a special time series mode, where the complex video returns were stored for each transmitted pulse and for each resolution volume.

The specific attenuation (at $10 \mathrm{GHz}$ ) scatter plot is shown in Fig. 9. The $B=-0.17 \mathrm{dBkm}^{-1}$ and FSE $=40 \%$ (corresponds to rms error of $0.49 \mathrm{dBkm}^{-1}$ ). As described in the Appendix, a new range-filtering algorithm was used to

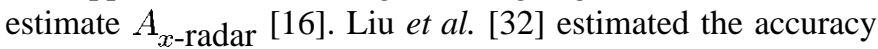
of specific attenuation estimates using this algorithm to be around $\pm 0.25 \mathrm{dBkm}^{-1}$ by using vertical pointing data from August 24, 1991, in homogeneous light rain conditions (where the mean $A_{x}$ should tend to zero, thus, revealing errors due to algorithm bias and statistical fluctuations). Note that radar constant biases will not contribute to the error. In the narrow rainshafts (typically $2-4 \mathrm{~km}$ ) of this present case, the cumulative attenuation is not large (typically $10 \mathrm{~dB}$ ), which makes it difficult to estimate $A_{x}$ accurately. Aydin et al. [14] estimated the accuracy of the algorithm to be around $\pm 0.5 \mathrm{dBkm}^{-1}$ (based on data from Colorado using the CP-2 radar), which is consistent with the results in Fig. 9. We believe these are the first results comparing radar estimates of $A_{x}$ directly with aircraft dsd measurements. These results give confidence in the new algorithm of Hubbert and Bringi [16], which is an iterative range-filtering technique using finite impulse response filters.

Jameson [33] has derived a third-order polynomial fit relating $D_{m}$ to $Z_{\mathrm{dr}}$ (in linear scale) based on gamma dsd's and the $a / b=1.03-0.062 D_{\text {eq }}$ relation for axis ratio. The solid line in Fig. 10 shows this polynomial relation. This figure also shows a scatter plot of $\left\langle D_{m}\right\rangle_{\mathrm{dsd}}$ (computed for each of the nine WKA size spectra) versus $\left\langle Z_{\mathrm{dr}}\right\rangle_{\text {radar }}$ (averaged $Z_{\mathrm{dr}}$ along the track from radar measurements) in linear scale. Note that the experimental mean axis ratio versus $D_{\text {eq }}$ curve in Fig. 3(a) is not used in constructing Fig. 10. The experimental data are in good agreement with Jameson's [33] simulated result. The bias between $D_{m \text {-radar (via the polynomial fit) }}$ and $D_{m \text {-dsd }}$ is only $0.07 \mathrm{~mm}$, while the standard deviation is $0.35 \mathrm{~mm}$ (FSE $=13.7 \%$ ). This result of negligible bias suggests that collision-induced large drop oscillations are not significant. The FSE value obtained here is in good

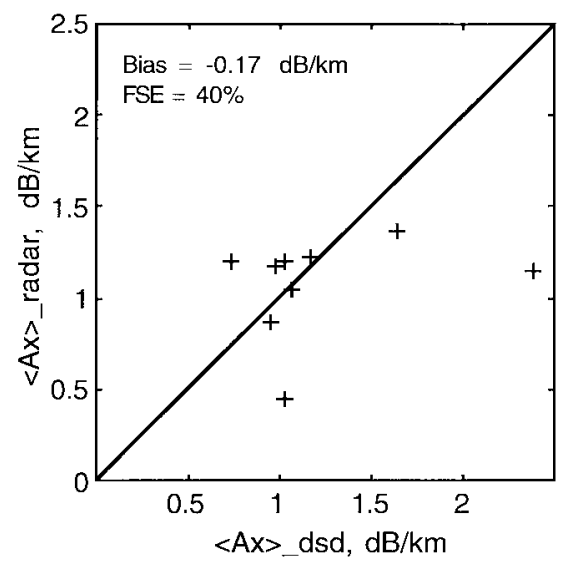

Fig. 9. As in Fig. 8, except scatterplot of X-band specific attenuation $\left(A_{x}\right)$ is shown.

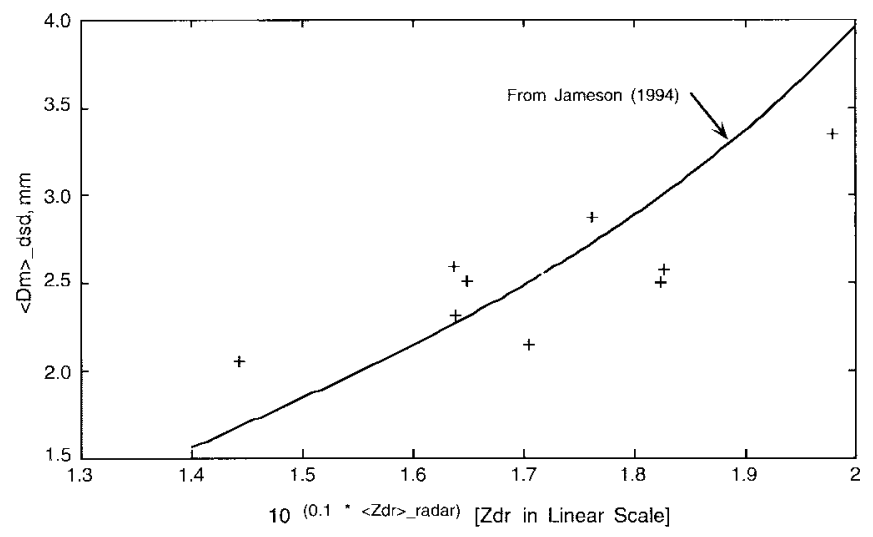

Fig. 10. Scatter plot of mass-weighted mean diameter computed from penetration-averaged dsd $\left(\left\langle D_{m}\right\rangle_{\mathrm{dsd}}\right)$ versus penetration-averaged radar measured $Z_{\mathrm{dr}}\left(\left\langle Z_{\mathrm{dr}}\right\rangle_{\text {radar }}\right)$ in linear scale. The solid line is from simulations of Jameson [33].

agreement with Jameson's [Fig. 4(b)], which gives the average fractional error of the estimate of $D_{m}$ inclusive of gamma distribution fluctuations and $Z_{\mathrm{dr}}$ measurement errors $\left(\Delta Z_{\mathrm{dr}}\right)$. Using an average value of $D_{m \text {-dsd }}=2.55 \mathrm{~mm}$ from all nine penetrations in Jameson's, Fig. 4 gives $\Delta D_{m} / D_{m}=10.1 \%$ (for $\Delta Z_{\mathrm{dr}}=0.1 \mathrm{~dB}$ ) and $17.9 \%$ (for $\Delta Z_{\mathrm{dr}}=0.2 \mathrm{~dB}$ ). Note that the experimentally-derived FSE of $13.7 \%$ falls within the two simulated values. These results are comparable to the only two known earlier ground-based results of Aydin et al. [11] and Goddard and Cherry [9] in light rainfall, who obtained FSE's in the range $10-15 \%$ for the prediction of median volume diameter $\left(D_{0}\right)$ from radar $Z_{\mathrm{dr}}$ measurements.

Several rainrate algorithms were tested next. These include the following:

1) $Z_{h}-R$ relation from Sekhon and Srivastava [34] used by Jameson [33] in his simulations, $R=0.0146\left(Z_{h}\right)^{0.741}$;

2) sixth order polynomial fit of $Z_{h} / R$ versus $Z_{\mathrm{dr}}$ by Jameson [33]; and

3) relation proposed by Gorgucci et al. [15] that fits the parameters of a relation $R=C_{2} Z_{h}^{\beta} 10^{-\nu} Z_{\mathrm{clr}}$ based on a cumulative distribution function (cdf) matching criteria for rainfall by using data from radar and raingages for a 1-h convective event that occurred on July 26, 1991, during CaPE. 
Their fitted equation is $R\left(Z_{h}, Z_{\mathrm{dr}}\right)=0.01\left(Z_{h}\right)^{0.914}$ $10^{-0.377 Z_{\mathrm{dr}}}$. Note that in the above equation $Z_{h}$ is in $\mathrm{mm}^{6} \mathrm{~m}^{-3}$, while $Z_{\mathrm{dr}}$ is in decibels. The above three rainfall estimates are termed $R\left(Z_{h}\right)_{\mathrm{SS}}$ (for Sekhon-Srivastava [34]), $R\left(Z_{h}, Z_{\mathrm{dr}}\right)_{\mathrm{JAM}}$ (for Jameson [33]), and $R\left(Z_{h}, Z_{\mathrm{dr}}\right)_{\mathrm{cdf}}$ (from Gorgucci et al. [15]).

Fig. 11(a)-(c) show the scatter plot of radar-based rainrates versus $\langle R\rangle_{\mathrm{dsd}}$ using the three estimators. In Fig. 11(a), the $B=20.6 \mathrm{mmh}^{-1}$ and $\mathrm{FSE}=70.4 \%$. From the error simulations of Jameson [33] for the average fractional error $(\Delta R / R)$ versus $D_{m}$, the $R\left(Z_{h}\right)_{S S}$ estimator gives a FSE $=75 \%$ at $D_{m}=2.55 \mathrm{~mm}$ in good agreement with the measured FSE of $70.4 \%$. The $Z_{h}$ measurement error in the simulations were assumed to be $\pm 1.0 \mathrm{~dB}$. In Fig. 11(b), the $B=0.33 \mathrm{mmh}^{-1}$, a drastic reduction from the value of $20.6 \mathrm{mmh}^{-1}$ in Fig. 11(a), which shows the added information contributed by $Z_{\mathrm{dr}}$. The FSE is also reduced to $37.1 \%$ in good agreement with simulated FSE of $42 \%$ in Jameson [33] at $D_{m}=2.55 \mathrm{~mm}$. Finally, in Fig. 11(c), we show the results for $\left\langle R\left(Z_{h}, Z_{\mathrm{dr}}\right)\right\rangle_{\mathrm{cdf}}$. The $B=1.4 \mathrm{mmh}^{-1}$ and FSE $=$ $31.8 \%$; this FSE being the smallest among the three estimators considered, perhaps, because the Gorgucci et al. [15] estimator is based on cdf matching for a rainfall event from the same $\mathrm{CaPE}$ regime, as in the present study (convective rainfall events from July 26 and August 8, respectively). The results obtained here for the FSE using $R\left(Z_{h}, Z_{\mathrm{dr}}\right)$ are consistent with the raingage comparison reported by Aydin et al. [13], who obtained an FSE of $38 \%$ in a rainfall event lasting 30 min, with rainrates in the range $20-40 \mathrm{mmh}^{-1}$.

Two recent studies involving $K_{\mathrm{dp}}$ rainrate estimators were compared against raingage accumulations over periods of $1-2 \mathrm{~h}$ in convective events known to contain small hail. In the Aydin et al. [14] study, one event with one weighing bucket raingage was analyzed for rainfall accumulation over an 80-min period using $R\left(K_{\mathrm{dp}}\right)$ from the Colorado State University (CSU)-CHILL radar and $R\left(A_{x}\right)$ from the CP-2 radar. Both algorithms predicted the total gage accumulation of $73 \mathrm{~mm}$ to within 10\%. The Ryzhkov and Zrnic [6] study involved 2-h rainfall accumulations over 42 gages in a squallline event with small hail. They report an FSE of around $20 \%$ for $R\left(K_{\mathrm{dp}}, Z_{\mathrm{dr}}\right)$ estimators when comparing 2-h rainfall accumulations. Because $K_{\mathrm{dp}}$ is independent of the radar constant and $Z_{\mathrm{dr}}$ can be accurately calibrated to within $0.1 \mathrm{~dB}$ (because it is a differential power measurement), estimators using both $K_{\mathrm{dp}}$ and $Z_{\mathrm{dr}}$ should outperform estimators that use $Z_{h}$ and $Z_{\mathrm{dr}}$. This was pointed out nearly two decades ago by Seliga and Bringi [35].

\section{CONCLUSION}

Coordinated analysis of aircraft 2-D-PMS probe observations of raindrops with multiparameter radar measurements in a multicellular storm have yielded valuable results concerning the accuracy of multiparameter radar estimates of $D_{m}$ and rainrate and the accuracy of estimating $A_{x}$ from dual-frequency reflectivity data. By analyzing nine aircraft penetrations in rainshafts (with rates in the range 10-60 $\mathrm{mmh}^{-1}$ ), it was determined that, using $Z_{\mathrm{dr}}$, the mass-weighted

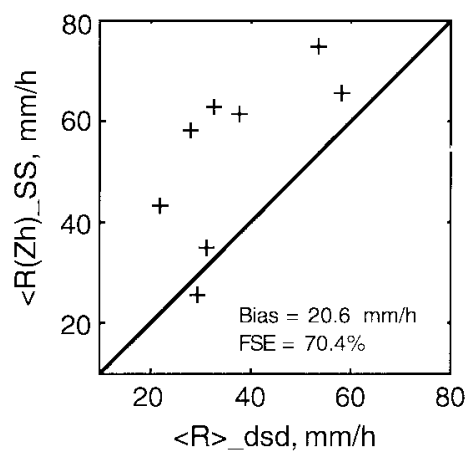

(a)

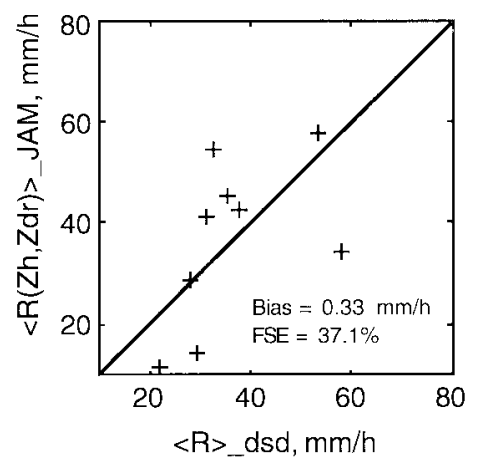

(b)

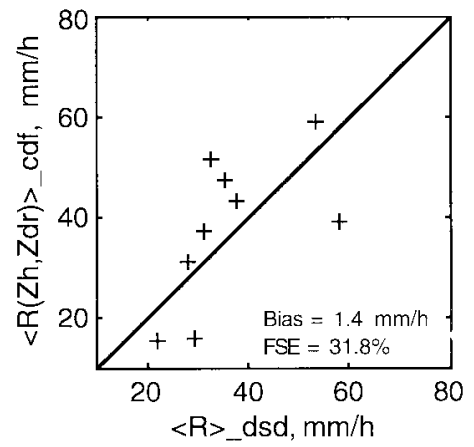

(c)

Fig. 11. (a) Scatter plot of (penetration-averaged) rainfall rate computed from radar measured $Z_{h}$ using the Sekhon and Srivastava [34] relation $R=0.0146 Z_{h}^{0.741}$ versus rainfall rate computed from (penetration-averaged) dsd $\left(\langle R\rangle_{\mathrm{dsd}}\right)$. (b) As in (a), except ordinate corresponds to rainfall rate from radar measured $Z_{h}$ and $Z_{\mathrm{dr}}$ given by Jameson [33]. (c) As in (a), except ordinate corresponds to rainfall rate from radar measured $Z_{h}$ and $Z_{\mathrm{dr}}$ given by Gorgucci et al. [15].

mean diameter of the size distribution $\left(D_{m}\right)$ could be estimated with a mean bias of $0.07 \mathrm{~mm}$ and a standard deviation of $0.35 \mathrm{~mm}$. These results are in excellent agreement with Jameson's [33] simulations for the average fractional error in estimating $D_{m}$ (using $Z_{\mathrm{dr}}$ ), considering gamma size distribution fluctuations and measurement errors. Several rainrate algorithms were considered, such as $R\left(Z_{h}\right)$ and $R\left(Z_{h}, Z_{\mathrm{dr}}\right)$. As expected, the $R\left(Z_{h}\right)$ estimator gave FSE $=$ $70 \%$ and normalized bias $=55 \%$. The $R\left(Z_{h}, Z_{\mathrm{dr}}\right)$ estimator from Gorgucci et al. [15] gave FSE $=32 \%$ and normalized bias $=4 \%$. The results using the $R\left(Z_{h}, Z_{\mathrm{dr}}\right)$ estimator from Jameson [33] gave FSE $=37 \%$ and normalized bias $=1 \%$, which are in excellent agreement with his simulations. The dual-frequency radar estimates of $A_{x}$ using a new, adaptive 
filtering algorithm described by Hubbert and Bringi [16] were directly compared with $A_{x}$, computed from size distributions yielding $\mathrm{FSE}=40 \%$ and normalized bias $=14 \%$. The rms error corresponds to $0.5 \mathrm{dBkm}^{-1}$, which is quite good considering the small cumulative attenuation $(\sim 10 \mathrm{~dB})$ in rainshafts considered here.

Raindrop axis ratios of nearly 3500 drops (with $D_{\text {eq }}>1.5 \mathrm{~mm}$ ) were estimated from the 2-D-PMS probe images and compared with the earlier results of Chandrasekar et al. [7] from the High Plains. Good consistency was obtained for the mean axis ratio versus $D_{\mathrm{eq}}$ relation between the High Plains (rainrate 1-15 $\mathrm{mmh}^{-1}$ ) and Florida (rainrate 10-60 $\mathrm{mmh}^{-1}$ ) data sets and with the model results of Beard and Chuang [2] for equilibrium-shaped drops. Drop oscillations were studied via a histogram of measured $(a / b) /\langle a / b\rangle$ for all drops with $D_{\mathrm{eq}}>1.5 \mathrm{~mm}$. These showed excellent consistency between the High Plains and Florida data sets. Most of the drops were observed to have axis ratios very close to their mean values (the mode of the histogram was close to unity), with oscillation amplitudes to be typically $\pm 10 \%$ in axis ratio for rainrates in the range $10-60 \mathrm{mmh}^{-1}$.

\section{APPENDIX}

The NCAR CP-2 radar used in this study is described, for example, in Bringi and Hendry [36]. The raw data from the radar analyzed here consists of range profiles of horizontally polarized reflectivity $\left(Z_{h}\right)$, the differential reflectivity $\left(Z_{\mathrm{dr}}\right)$, and the dual-frequency reflectivity ratio (DFR) at the two frequencies (10 and $3 \mathrm{GHz}$ ). The accuracy in estimates of $Z_{h}( \pm 1 \mathrm{~dB})$ and $Z_{\mathrm{dr}}( \pm 0.25 \mathrm{~dB})$ are standard (see, for example, Doviak and Zrnić [37]). From the range profiles of DFR, the specific attenuation at X-band is calculated using an "adaptive" range-filtering technique described by Hubbert and Bringi [16]. In uniform rainfall, the accuracy in $A_{x}$ using this method was determined to be around $\pm 0.25 \mathrm{dBkm}^{-1}$ by Liu et al. [32]. In the small rainshafts $(2-4 \mathrm{~km})$ studied here (with strong gradients), the accuracy is estimated to be around $\pm 0.5 \mathrm{dBkm}^{-1}$ (see Aydin et al. [14]). The $A_{x}$ can be related to rainrate $R$ via $R=54.6\left(A_{x}\right)^{0.845}\left(\mathrm{mmh}^{-1}\right)$, which is a temperature-averaged relation derived by Jameson [38].

The system bias in $Z_{\text {dr }}$ was evaluated using vertical incidence observations under conditions of light rainfall, which were taken on August 24, 1991 (a few days after the CaPE project ended, but the CP-2 radar was still at its same location in Florida). Because this system bias $(0.5 \mathrm{~dB})$ can change by a few tenths of a decibel, due to changes in the differential insertion loss of the polarization switch, the $Z_{\mathrm{dr}}$ bias was further fine-tuned for the August 8 case by constructing height profiles of $Z_{\mathrm{dr}}$ averaged over the entire storm area for each volume of data at roughly 3-min intervals from 1740 to 1813 UTC. In the ice region near the top of the storm, the average $Z_{\mathrm{dr}}$ should approach $0 \mathrm{~dB}$ because of random orientation of the ice particles and/or because of their lower density. This fine-tuned adjustment to the $Z_{\mathrm{dr}}$ bias amounted, on average, to $-0.082 \mathrm{~dB}$ (standard deviation $=0.035 \mathrm{~dB}$ ), resulting in an overall system bias for August 8 of $0.418 \mathrm{~dB}$.
The S-band radar constant of the CP-2 radar was adjusted from the nominal value of $73.3 \mathrm{~dB}$ [39] using the technique described in Chandrasekar et al. [5], which is a variant of the scheme discussed in Aydin et al. [40]. The rain medium is used as a "calibration" medium, i.e., rainrate computed from $\left(Z_{h}, Z_{\mathrm{dr}}\right)$ is plotted versus rainrate from $K_{\mathrm{dp}}$. Since $K_{\mathrm{dp}}$ is insensitive to the radar constant (being a differential phase measurement) and $Z_{\mathrm{dr}}$ can be accurately adjusted for system bias being a differential power measurement, any deviation of $R\left(Z_{h}, Z_{\mathrm{dr}}\right)$ from $R\left(K_{\mathrm{dp}}\right)$ away from the $1: 1$ line can be attributed to the radar constant. Thus, by finetuning the radar constant, it is possible to correct for any systematic overprediction or underprediction of $R\left(Z_{h}, Z_{\mathrm{dr}}\right)$, relative to $R\left(K_{\mathrm{dp}}\right)$. Time series data were collected in a special data acquisition mode on August 24, 1991, in a squallline-type rainfall event from which $K_{\mathrm{dp}}$ could be derived. This procedure resulted in an adjustment to the nominal radar constant of $3.73 \mathrm{~dB}$, i.e., from 73.3 to $69.57 \mathrm{~dB}$. Wilson et al. [39], using a scheme of intercomparing reflectivities from the three NCAR radars (CP-2, 3, and 4) in carefully selected precipitation echoes, found that the $\mathrm{CP}-2$ radar constant should be adjusted downward by 1.5 to $3.0 \mathrm{~dB}$, which is consistent with the direction and magnitude of our adjustment of $3.73 \mathrm{~dB}$.

The multiparameter fields $Z_{h}, Z_{\mathrm{dr}}$, and $A_{x}$ are interpolated onto a Cartesian grid by using the NCAR REORDER software package. A relatively fine spacing was used $(250 \mathrm{~m}$ in the three directions). A Cressman weighting scheme was used with a 250-m horizontal radius and a 500-m vertical radius for data acquired in PPI mode; for data in RHI mode, the horizontal radius was set to $500 \mathrm{~m}$ and the vertical radius to $250 \mathrm{~m}$. The NCAR CEDRIC software was used to further analyze and display the fields.

\section{ACKNOWLEDGMENT}

The CP-2 radar was operated by NCAR during CaPE. The University of Wyoming operated the King Air aircraft. The assistance of Dr. L. Liu (formerly at CSU) in the radar data processing is gratefully acknowledged. The authors also acknowledge useful discussions with Dr. W. Cooper and J. Fankhauser of NCAR and Prof. R. Srivastava of the University of Chicago.

\section{REFERENCES}

[1] H. R. Pruppacher and K. V. Beard, "A wind tunnel investigation of the internal circulation and shape of water drops falling at terminal velocity in air," Q. J. R. Meteorol. Soc., vol. 96, pp. 247-256, 1970.

[2] K. V. Beard and C. Chuang, "A new model for the equilibrium shape of raindrops," J. Atmos. Sci., vol. 44, pp. 1509-1524, 1987.

[3] T. A. Seliga and V. N. Bringi, "Potential use of radar differential reflectivity measurements at orthogonal polarizations for measuring precipitation," J. Appl. Meteorol., vol. 15, pp. 69-76, 1976.

[4] C. W. Ulbrich, "Natural variations in the analytical form of the raindropsize distribution," J. Clim. Appl. Meteorol., vol. 22, pp. 1764-1775, 1983.

[5] V. Chandrasekar, V. N. Bringi, N. Balakrishnan, and D. S. Zrnic, "Error structure of multiparameter radar and surface measurements of rainfall. Part III: Specific differential phase," J. Atmos. Ocean. Technol., vol. 6, pp. 476-486, 1990.

[6] A. V. Ryzhkov and D. S. Zrnic, "Comparison of dual-polarization radar estimations of rain," J. Atmos. Ocean. Technol., vol. 12, pp. 249-256, 1995. 
[7] V. Chandrasekar, W. A. Cooper, and V. N. Bringi, "Axis ratios and oscillations of raindrops," J. Atmos. Sci., vol. 45, pp. 1323-1333, 1988

[8] K. V. Beard, D. B. Johnson, and A. R. Jameson, "Collisional forcing of raindrop oscillations," J. Atmos. Sci., vol. 40, pp. 455-462, 1983.

[9] J. W. F. Goddard and S. M. Cherry, "The ability of dual-polarization radar (copolar linear) to predict rainfall rate and microwave attenuation," Radio Sci., vol. 19, pp. 201-208, 1984.

[10] K. V. Beard, R. J. Kubesh, and H. T. Ochs, III, "Laboratory measurements of small raindrops distortion part I: Axis ratio and fall behavior," J. Atmos. Sci., vol. 48, pp. 698-710, 1991.

[11] K. Aydin, H. Direskeneli, and T. A. Seliga, "Dual polarization radar estimation of rainfall parameters compared with ground-based distrometer measurements: 29 Oct. 1982 Central Illinois experiment," IEEE Trans. Geosci. Remote Sensing, vol. GE-25, pp. 834-844, Sept. 1987.

[12] S. M. Cherry and J. W. F. Goddard, "Simultaneous measurements of rain by airborne distrometer and dual-polarization radar," Radio Sci. vol. 19, pp. 169-176, 1984

[13] K. Aydin, Y. M. Lure, and T. A. Seliga, "Polarimetric radar measurements of rain-fall compared with ground-based rain gauges during MAYPOLE'84," IEEE Trans. Geosci. Remote Sensing, vol. 28, pp. 443-449, May 1990

[14] K. Aydin, V. N. Bringi, and L. Liu, "Rain-rate estimation in the presence of hail using S-band specific differential phase and other radar parameters," J. Appl. Meteorol., vol. 34, pp. 404-410, 1995.

[15] E. Gorgucci, V. Chandrasekar, and G. Scarchilli, "Radar and surface measurement of rainfall during CaPE: 26 July 1991 case study," $J$. Appl. Meteorol., vol. 34, pp. 1570-1577, 1995.

[16] J. Hubbert and V. N. Bringi, "An Iterative filtering technique for the analysis of copolar differential phase and dual-frequency radar measurements," J. Atmos. Ocean. Technol., vol. 12, pp. 634-648, 1995.

[17] V. N. Bringi, L. Liu, P. C. Kennedy, V. Chandrasekar, and S. A. Rutledge, "Dual multiparameter radar observations of intense convective storms: The 24 June 1992 case study," J. Met. Atmos. Phys., vol. 59, pp. 3-31, 1996

[18] S. E. Yuter and R. A. Houze, Jr., "Three-dimensional kinematic and microphysical evolution of Florida cumulonimbus. Part II: Frequency distributions of vertical velocity, reflectivity and differential reflectivity," Mon. Weath. Rev., vol. 123, pp. 1941-1963, 1995.

[19] J. F. French, J. H. Helsdon, A. G. Detwiler, and P. L. Smith, "Microphysical and electrical evolution of a Florida thunderstorm. Part I: Observations," J. Geophys. Res., vol. 101, pp. 18961-18 977, 1996

[20] R. Ramachandran, A. Detwiler, J. Helsdon Jr., P. L. Smith, and V. N. Bringi, "Precipitation development and electrification in Florida thunderstorm cells during CaPE," J. Geophys. Res., vol. 101, no. D1, pp. 1599-1619, 1996.

[21] A. J. Illingworth, J. W. F. Goddard, and S. M. Cherry, "Polarization radar studies of precipitation development in convective storms," $Q . J$. R. Meteorol. Soc., vol. 113, pp. 469-489, 1987.

[22] J. D. Tuttle, V. N. Bringi, H. D. Orville, and F. J. Kopp, "Multiparameter radar study of a microburst: Comparison with model results," J. Atmos. Sci., vol. 46, pp. 601-620, 1989.

[23] R. Xiao, V. Chandrasekar, and D. Garbrick, "Ellipse-fitting techniques applied to 2D-PMS raindrop images," J. Atmos. Ocean. Technol., vol. 12, pp. 1338-1347, 1995.

[24] J. S. Marshall and W. M. Palmer, "The distribution of raindrops with size," J. Meteorol., vol. 5, pp. 165-166, 1948.

[25] R. J. Kubesh and K. V. Beard, "Laboratory measurements of spontaneous oscillations for moderate-size raindrops," J. Atmos. Sci., vol. 50, pp. 1089-1098, 1993.

[26] R. Clift, J. R. Grace, and M. E. Weber, Bubbles, Drops and Particles. New York: Academic, 1978, p. 380.

[27] A. Tokay and K. V. Beard, "A field study of raindrop oscillations. Part I: Observation of size spectra and evaluation of oscillation causes," $J$. Appl. Meteorol., vol. 35, pp. 1671-1687, 1996.

[28] A. R. Jameson, "Microphysical interpretation of multiparameter radar measurements in rain. Part I: Interpretation of polarization measurements and estimation of raindrop shapes," J. Atmos. Sci., vol. 40, pp. $1792-1802,1983$

[29] Z. Hu and R. C. Srivastava, "Evolution of raindrop size distribution by coalescence, breakup and evaporation: Theory and observations," $J$. Atmos. Sci., vol. 52, pp. 1761-1783, 1995.

[30] P. Barber and C. Yeh, "Scattering of electromagnetic waves by arbitrarily shaped dielectric bodies," Appl. Opt., vol. 14, pp. 2864-2872, 1975.

[31] P. S. Ray, "Broadband complex refractive indices of ice and water," Appl. Opt., vol. 11, pp. 1836-1844, 1972

[32] L. Liu, V. N. Bringi, I. J. Caylor, and V. Chandrasekar, "Intercomparison of multiparameter radar signature from Florida storms," in Preprints 26th Int. Conf. Radar Meteorol. Norman, OK: Amer. Meteorol. Soc., 1993, pp. 733-735.

[33] A. R. Jameson, "An alternative approach to estimating rainfall rate by radar using propagation differential phase shift," J. Atmos. Ocean. Technol., vol. 11, pp. 122-131, 1994.

[34] R. S. Sekhon and R. C. Srivastava, "Doppler radar observations of drop-size distributions in a thunderstorm," J. Atmos. Sci., vol. 28, pp. 983-994, 1971.

[35] T. A. Seliga and V. N. Bringi, "Differential reflectivity and differential phase shift: Applications in radar meteorology," Radio Sci., vol. 13, pp. 271-275, 1978

[36] V. N. Bringi and Hendry, "Technology of polarization diversity radars for meteorology," in Radar in Meteorology, D. Atlas, Ed. Norman, OK: Amer. Meteorol. Soc., 1990, pp. 153-190.

[37] R. J. Doviak and D. S. Zrnic, Doppler Radar and Weather Observations, 2nd ed. New York: Academic, pp. 254-255, 1993.

[38] A. R. Jameson, "The effect of temperature on attenuation correction schemes in rain using polarization propagation differential phase shift," J. Appl. Meteorol., vol. 30, pp. 1106-1118, 1992.

[39] J. W. Wilson, T. M. Weckwerth, J. Vivekanandan, R. M. Wakimoto, and R. W. Russell, "Boundary layer clear-air radar echoes: Origin of echoes and accuracy of derived winds," J. Atmos. Ocean. Technol., vol. 11, pp. 1184-1206, 1994.

[40] K. Aydin, T. A. Seliga, C. P. Cato, and M. Arai, "Comparison of measured X-band reflectivity factors with those derived from S-band measurements at horizontal and vertical polarizations," in Preprints 21 st Conf. Radar Meteorol. Edmonton, Alta., Canada: Amer. Meteorol. Soc., 1983, pp. 513-517.

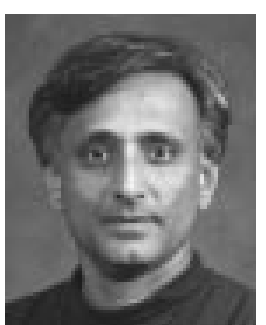

V. N. Bringi received the B.Tech. (Hons.) degree in electrical engineering from the Indian Institute of Technology, Bombay, India, in 1971 and the Ph.D. degree in electrical engineering from The Ohio State University, Columbus, in 1976

He joined Colorado State University (CSU), For Collins, in 1981 as an Associate Professor and was promoted to the rank of Full Professor in 1987 His research interests are in application of radar polarimetry to meteorology. He is Co-Principal Investigator for the CSU-CHILL national radar facility operated by the CSU under a five-year cooperative agreement with the National Science Foundation. He is currently an Associate Editor of the Journal of Atmospheric and Oceanic Technology.

Dr. Bringi has served on the American Meteorological Society's Committee on Radar Meteorology.

V. Chandrasekar (S'83-M'83), photograph and biography not available at the time of publication.

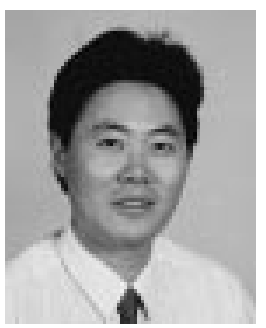

Rongrui Xiao (S'94-M'96) was born in Jiangxi, China, in 1964. He received the B.S. and M.S. degrees from Shanghai Jiao Tong University, Shanghai, China, in 1985 and 1988, respectively, and the Ph.D. degree from Colorado State University (CSU), Fort Collins, in 1996, all in electrical engineering.

He was with the Shanghai Broadcasting and TV Technology Research Institute between 1988 and 1991. From 1992 to 1996, he was a Graduate Research Assistant in the Department of Electrical Engineering, CSU. He worked as a Post-Doctoral Research Fellow in the Radar Laboratory, Department of Electrical Engineering, CSU, after he graduated. He joined Vexcel Corporation, Boulder, CO, in December 1996. He is currently involved in research and development of advanced SAR processing algorithms and satellite ground station for remote sensing. His research interests include signal processing, image processing, neural networks, pattern recognition, and radar remote sensing.

Dr. Xiao is a member of Sigma Xi. 